\title{
Partition of Rare Earth Elements Between Sulfate Salts Formed by the Evaporation of Acid Mine Drainage
}

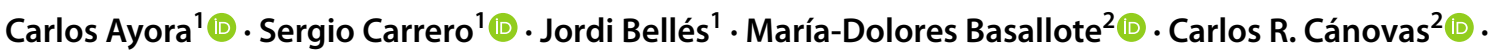 \\ Francisco Macías ${ }^{2}$ (])
}

Received: 2 January 2021 / Accepted: 28 July 2021

(c) Springer-Verlag GmbH Germany, part of Springer Nature 2021

\begin{abstract}
Acid mine drainage (AMD) contains rare earth element (REE) concentrations several orders of magnitude higher than those of the rest of natural waters and could be a secondary source of REEs. In arid to semiarid climates with a long dry season, the precipitation of efflorescent sulfates constitutes a transient storage of REEs. The REE partition among the $\mathrm{Al}-\mathrm{Fe}-\mathrm{Mg}-$ $\mathrm{Ca}$ sulfates formed by the evaporation to dryness of six different AMDs was investigated by statistical methods and by selective dissolution. The chemical composition of the evaporitic salts showed that only three principal components (PCs) could explain more than $80 \%$ of the variability in the six samples analyzed. PC1 was associated with Ca and light REEs and interpreted as gypsum, whereas PC2 was associated with Y and heavy REEs, which were not clearly associated with a major sulfate. Finally, PC3 included Mg, Fe and several transition metals (Cu, Ni, Co, Mn and $\mathrm{Zn}$ ) and was interpreted as Fe(II)-Mg sulfates. Selective dissolution of the salt mixtures with solutions saturated in the major sulfates revealed that the REEs were only retained in gypsum and were practically absent from the rest of the sulfates. The incorporation of REEs into gypsum decreased from Pr-Nd to $\mathrm{La}$ and $\mathrm{Lu}$ and was strictly ruled by the differences in their atomic radii and that of Ca in eight-fold coordination. However, gypsum concentrated less than $20 \%$ of the REE inventory $(<1 \%$ for Sc); the rest probably formed one or more unidentified trace minerals. This indicates that gypsum may not be an efficient way to concentrate REEs from AMD.
\end{abstract}

Keywords Gypsum $\cdot$ Exploratory factor analysis $\cdot$ Efflorescent salts $\cdot$ Coordination polyhedra $\cdot$ Fractionation factor

Carlos Ayora

caigeo@idaea.csic.es

Sergio Carrero

sergio.carrero@idaea.csic.es

Jordi Bellés

jordi.belles@idaea.csic.es

María-Dolores Basallote

maria.basallote@dct.uhu.es

Carlos R. Cánovas

carlos.ruiz@dgeo.uhu.es

Francisco Macías

francisco.macias@dgeo.uhu.es

1 Institute of Environmental Assessment and Water Research, CSIC, Jordi Girona 18, 08024 Barcelona, Spain

2 Department of Earth Sciences, University of Huelva, Campus El Carmen, 21071 Huelva, Spain

\section{Introduction}

The lanthanide series (from $\mathrm{La}$ to $\mathrm{Lu}$ ) plus scandium (Sc) and yttrium (Y) are referred to as the rare earth elements (REEs) (Connelly et al. 2005). The lanthanides show similar atomic structures and chemical properties, with a small decrease in ionic radius from $\mathrm{La}$ to $\mathrm{Lu}$. The lanthanides can be arbitrarily divided into light (LREE: La to Eu) and heavy (HREE: Gd to Lu), where Y and Sc are often considered with the HREEs due to their similar atomic size, although Sc has also been set aside by its small ionic radius (Chakhmouradian and Wall 2012).

The geochemistry of REEs has been extensively studied as tracer of geological processes (e.g. Elderfield et al. 1990; McLennan 1989; Migaszewski and Galuszka 2015). However, in the last two decades, there has been increasing interest due to their high demand in modern industry, particularly that related to green energy generation and consumption. The expected increase in demand and the 
existence of only one major producer make the finding of new sources of REE imperative (Alonso et al. 2012).

Acid mine drainage (AMD) is one of the most extensive and long-lasting pollutant processes of watersheds in the world (Nordstrom et al. 2015; Younger 1997). The oxidation of $\mathrm{Fe}$ sulfides generates acidic and sulfate-rich solutions that are very efficient in dissolving the aluminosilicates of the enclosing rocks. Therefore, the dissolution of rocks and the release of solutes to water are much more intense in AMD environments than in other weathering profiles. The low $\mathrm{pH}$ and aqueous complexation by sulfate inhibit the sorption of REEs in clays and stabilize them in solution. As a consequence, the REE concentrations in AMD could be several orders of magnitude higher than in any other natural waters (Noack et al. 2014). Since AMD is expected to last hundreds of years, the total reserves are virtually unlimited, and these waters could become a small but continuous source of REEs (Ayora et al. 2016; Hedin et al. 2019; Stewart et al. 2017; Vass et al. 2019a,b).

The mobility of REEs in AMD is $\mathrm{pH}$ dependent. When AMD effluents mix with alkaline river water and the $\mathrm{pH}$ increases to above 6, Fe and $\mathrm{Al}$ oxyhydroxides precipitate, retaining the total dissolved amount of REEs (Ferreira da Silva et al. 2009; Gammons et al. 2005; Lozano et al. 2019a, 2020a; Olías et al. 2018; Verplanck et al. 2004). Therefore, the precipitation of schwertmannite and particularly basaluminite can be considered an effective and long-lasting natural mechanism for REE removal from water. When AMD is neutralized with alkaline reagents in treatment plants, practically all REEs are retained in the sludge of schwertmannite, basaluminite and gypsum, resulting in a residue with REE concentrations similar to those of present-day mines and prospects (Ayora et al. 2016; Lozano et al. 2020b; Macías et al. 2017; Vass et al. 2019a,b; Zhang and Honaker 2018, 2020).

In arid to semiarid climates with a long dry season, the precipitation of soluble sulfate salts can also remove sulfate, acidity, and metals from AMD (Alpers et al. 1994; Hammarstrom et al. 2005; Jambor et al. 2000). This precipitation, caused by evapoconcentration processes, occurs on wet surfaces at riverbanks, seeps, and rock fractures, and in the pores of waste dumps and tailings where upward migration of water by capillary action (efflorescence) seems to be the dominant process (Olyphant et al. 1991). The formation of these efflorescent salts constitutes a transient storage of metals. Indeed, the dissolution of these salts with the first rainfalls causes rapid acidification and the release of enormous amounts of sulfate and metals to the watersheds (Bayless and Olyphant 1993; Cánovas et al. 2008, 2010; Jerz and Rimstidt 2003).

Several studies have described the mineralogy and precipitation/dissolution processes of these efflorescent salts in the field (Buckby et al. 2003; Hammarstrom et al. 2005;
Moncur et al. 2015). Although different trace metals such as $\mathrm{Zn}, \mathrm{Cu}, \mathrm{Co}, \mathrm{Mn}, \mathrm{Ni}$, or $\mathrm{Cd}$ may form individual sulfates, most of them have been described to substitute for the major cation in $\mathrm{Mg}$ and $\mathrm{Fe}$ sulfates (Hammarstrom et al. 2005; Jambor et al. 2000).

Despite the interest in REE behavior in AMD environments, their partition between water and efflorescent sulfates has not been addressed, although it has been observed that these elements are mobile after washing events. It was initially assumed that REEs are incorporated in major sulfates (e.g. $\mathrm{Fe}, \mathrm{Al}, \mathrm{Mg}$, or $\mathrm{Ca}$ ) because REE sulfates are very rare (Hammarstrom et al. 2005). Thus, only three efflorescent REE-sulfates have been described on the surface of pyrite-bearing phyllites from Alum Cave Bluff, TN, USA (Peacor et al. 1999; Rouse et al. 2001): levinstonite $(\mathrm{Y}, \mathrm{Nd}, \mathrm{Ce}) \mathrm{Al}\left(\mathrm{SO}_{4}\right)_{2}\left(\mathrm{C}_{2} \mathrm{O}_{4}\right) \cdot 12 \mathrm{H}_{2} \mathrm{O}$; coskrenite $(\mathrm{Ce}, \mathrm{Nd}$, $\mathrm{La})_{2}\left(\mathrm{SO}_{4}\right)_{2}\left(\mathrm{C}_{2} \mathrm{O}_{4}\right) \cdot 8 \mathrm{H}_{2} \mathrm{O}$; and zugshunstite $(\mathrm{Ce}, \mathrm{Nd}, \mathrm{La})$ $\mathrm{Al}\left(\mathrm{SO}_{4}\right)_{2}\left(\mathrm{C}_{2} \mathrm{O}_{4}\right) \cdot 12 \mathrm{H}_{2} \mathrm{O}$. Very interestingly, the first mineral preferentially accommodates HREEs, whereas the other two tend to host LREEs. The three minerals have similar structures, consisting of chains of alternating REE polyhedra and oxalate groups, with two sulfate tetrahedra associated with each REE polyhedron. The REE polyhedra are formed by eight ligands in levinstonite and nine in zugshunstite and coskrenite, in accordance with the increasing ionic radius from HREE to LREE. Due to the presence of similar Ca polyhedra with eight ligands in gypsum and the absence of similar polyhedra in the rest of the major $\mathrm{Al}, \mathrm{Fe}$, and $\mathrm{Mg}$ sulfates (Hawthorne et al. 2000), REEs could show some preference to be incorporated into gypsum. This feature could have unexplored practical applications in REEs concentration and extraction different from the chemically intensive conventional technologies.

In accordance with this, Inguaggiato et al. (2018) described a clear association of REEs with gypsum precipitated from the acid sulfate-rich waters of the Poas volcano in Costa Rica. Basallote et al. (2019) investigated REE partitioning among dissolved and solid phases during laboratory-induced evaporation of the acidic waters of the AMDaffected Agrio River (SW Spain). From statistical analysis, these authors also concluded that REEs seem to have some affinity with gypsum with the exceptions of $\mathrm{Y}$ and Sc, which could be associated with Fe sulfates. However, no clearer conclusions could be extracted, probably due to the difficulty of completely isolating solid phases from a dense and viscous brine in the advanced stages of evaporation.

Therefore, we investigated the partition of REEs among the main sulfates formed after complete evaporation of six different AMDs with very different proportions of major solutes ( $\mathrm{Al}, \mathrm{Ca}, \mathrm{Mg}$, and $\mathrm{Fe}$ ). Imitating field observations in the dry season, the AMDs were evaporated to dryness, and the resulting mixtures of sulfates were analyzed for major and trace elements. Due to the difficulty of separating and 
identifying trace minerals in multicomponent complex matrices, the association of REEs with the major solutes was investigated by statistical methods and by selective dissolution of major sulfates.

\section{Materials and Methods}

\section{Experimental}

Six AMD samples from different sites of the Iberian pyrite belt (IPB, SW Spain) were selected: Agrio (AG), Sabina (SA), Esperanza (ES), Monte-Romero (MR), Perrunal (PE), and Poderosa (PO). The location and complete chemical analyses of each sample are listed in Table 1. Five of the samples (SA, ES, MR, PE, and PO) were collected at the outflows of ancient mine galleries, in which $\mathrm{Fe}(\mathrm{II})$ was highly predominant over $\mathrm{Fe}(\mathrm{III})$. One sample, however, was collected from the Agrio River, several kilometers downstream of the Riotinto waste dumps, and the proportion of $\mathrm{Fe}(\mathrm{III})$ exceeded $50 \%$. Field parameters such as $\mathrm{pH}$, Eh, temperature (T), and electrical conductivity (EC) were measured in situ with properly calibrated Hanna portable instruments (probe types HI9025C, HI9033, and HI9025, respectively). The AMD samples were collected in $1 \mathrm{~L}$ highdensity polypropylene bottles full to the brim wrapped with Merck Parafilm ${ }^{\mathrm{TM}}$ to prevent oxidation and kept at $4{ }^{\circ} \mathrm{C}$ until the evaporation experiment. An aliquot of $100 \mathrm{~mL}$ was passed on site through a Millipore $0.20 \mu \mathrm{m}$ nylon filter and acidified with ultrapure $\mathrm{HNO}_{3}$ to a $\mathrm{pH}<2$ before analysis. A separate sample for $\mathrm{Fe}(\mathrm{II} / \mathrm{III})$ determination was acidified with concentrated $\mathrm{HCl}$.

Within two weeks after sampling, $300 \mathrm{~mL}$ of each AMD sample was evaporated to dryness in watch glasses $30 \mathrm{~cm}$ in diameter (Fig. 1). Evaporation took place at $35^{\circ} \mathrm{C}$ and under constant air current for 2-4 days depending on the sample. The humidity varied during the day between 35 and $65 \%$. The resulting salts were sampled progressively from the periphery to the center, and 20-33 solid samples were collected for each initial AMD. A number of solid samples were selected for microscopic observation based on their different appearance (color, morphology) and location in the watch glass. Then, two aliquots of the previously ground and homogenized solid samples were separated for mineralogical determination and chemical analysis. The latter aliquot was dissolved in Milli-Q water (0.05 mg in $20 \mathrm{~mL})$, acidified with $\mathrm{HNO}_{3}$ and stored for chemical analysis.

To investigate the preference of REEs for a particular solid sulfate, an additional experiment was designed to isolate each sulfate by selective dissolution of the others. To accomplish this, individual solutions saturated in the different major salts (gypsum, alunogen, hexahydrite, rozenite, and rhomboclase) were prepared. Thus, an amount of pure chemical reagent of each sulfate in excess of its solubility limit was added to an aliquot of $200 \mathrm{~mL}$ of distilled water and shaken for 7 days to ensure solution-salt equilibrium. Then, $300 \mathrm{~mL}$ of the Agrio (AG) sample was evaporated to dryness under the same conditions described above. To obtain enough material for all the tests, only three integrated salt samples were collected from the periphery to the center (X1, X2, and X3). The solid samples were ground and homogenized, and five aliquots of each solid sample were dissolved in Milli-Q water, and each of the five saturated solutions $(0.1 \mathrm{mg}$ in $50 \mathrm{~mL})$ were shaken for $24 \mathrm{~h}$. The aqueous phase and the residual solid were separated by centrifugation for $15 \mathrm{~min}$ at $4500 \mathrm{rpm}$ (4150 RCF), and the supernatant was filtered through a $0.1 \mu \mathrm{m}$ Whatman Puradisc 13 nylon membrane. The solids obtained after centrifugation were rinsed twice with ethanol to eliminate the remaining brine and divided into two different aliquots. One aliquot was analyzed by XRD, and the other aliquot was dissolved in a $25 \% \mathrm{HNO}_{3}$ solution and stored for chemical analysis.

\section{Analytical Techniques}

The solid samples obtained prior to grinding were observed under a JEOL $®$ JSM840 Field Emission Scanning Electron Microscope with an Oxford Link ${ }^{\circledR}$ Energy Dispersive System (FESEM-EDS).

The major mineral phases forming the solid samples were identified by X-ray diffraction (XRD) using a Bruker D8 A25 Advance diffractometer with $\mathrm{Cu} L \alpha$ radiation, Bragg-Brentano geometry, and a position-sensitive LynxEyeXE detector. The diffractograms were obtained at $40 \mathrm{kV}$ and $40 \mathrm{~mA}$, scanning from $4^{\circ}$ to $60^{\circ}$ of $2 \theta$ with a step size of $0.019^{\circ}$ and a counting time of $0.1 \mathrm{~s} /$ step maintaining the sample in rotation $(15 / \mathrm{min})$. Semi-quantitative XRD analysis was performed by using the RIR (reference intensity ratios) method (Snyder and Bish 1989). The RIR method employed corundum as the internal standard (RIRcor, Hubbard and Snyder 1988). Values of the RIR of the more intense peak of each phase with respect to the corundum (50:50) are reported in the PDF-2 database of the International Centre for Diffraction Data (Gaste-Rector and Blanton 2019). The crystalline phase identification and quantification were carried out by EVA software (Bruker).

The major cations and total sulfur were measured by ICPAES (Perkin-Elmer® Optima 3200 RL), and trace elements were measured by ICP-MS (Perkin-Elmer ${ }^{\circledR}$ Sciex Elan 6000). Detection limits ranged from $0.5(\mathrm{~K})$ to $0.02 \mathrm{mg} / \mathrm{L}$ (Mg, Zn, Mn) for ICP-AES and below $2 \mu \mathrm{g} / \mathrm{L}$ for ICP-MS, depending on the initial total dissolved solids of the solution. The analytical precision error was estimated as three times the background to be approximately $7 \%$ for ICP-AES 
Table 1 Chemical composition of the starting AMDs used in the evaporation experiments

\begin{tabular}{|c|c|c|c|c|c|c|}
\hline & Agrio & Esperanza & MonteRomero & Perrunal & Poderosa & Sabina \\
\hline UTM X & $703,481.4$ & $704,094.5$ & $694,253.9$ & $688,607.1$ & $705,558.1$ & $666,096.6$ \\
\hline UTM Y & $4,178,232.8$ & $4,181,643.0$ & $4,183,241.6$ & $4,175,224.2$ & $4,180,485.0$ & $4,161,063.6$ \\
\hline $\mathrm{pH}$ & 2.75 & 2.82 & 3.11 & 2.58 & 2.34 & 2.58 \\
\hline $\mathrm{EC}(\mu \mathrm{S} / \mathrm{cm})$ & 7250 & 4130 & 4646 & 5109 & 4816 & 6503 \\
\hline $\begin{array}{l}\mathrm{Eh}(\mathrm{mV}) \\
\mathrm{mg} / \mathrm{L}\end{array}$ & 657 & 556 & 430 & 535 & 418 & 529 \\
\hline $\mathrm{Al}$ & 1059 & 177 & 167 & 292 & 233 & 521 \\
\hline $\mathrm{Ca}$ & 376 & 168 & 283 & 224 & 106 & 64 \\
\hline $\mathrm{Cu}$ & 73 & 19 & 6 & 12 & 102 & 237 \\
\hline $\mathrm{Fe}(\mathrm{III})$ & 470 & 72 & 173 & 78 & 111 & 182 \\
\hline $\mathrm{Fe}(\mathrm{II})$ & 243 & 420 & 880 & 730 & 753 & 1180 \\
\hline $\mathrm{K}$ & 2.4 & 6.2 & 1.5 & 4.2 & 15.8 & 13.3 \\
\hline $\mathrm{Mg}$ & 1040 & 208 & 375 & 305 & 113 & 102 \\
\hline $\mathrm{Mn}$ & 96 & 11 & 56 & 91 & 3 & 20 \\
\hline $\mathrm{Na}$ & 20 & 26 & 37 & 27 & 15 & 40 \\
\hline $\mathrm{P}$ & 0.1 & 0.4 & 0.7 & 0.6 & 0.5 & 1.5 \\
\hline S & 3922 & 1048 & 1672 & 1572 & 1210 & 1746 \\
\hline $\mathrm{Si}$ & 41 & 47 & 40 & 45 & 42 & 43 \\
\hline $\mathrm{Zn}$ & 191 & 25 & 491 & 40 & 64 & 13 \\
\hline \multicolumn{7}{|l|}{$\mu \mathrm{g} / \mathrm{L}$} \\
\hline $\mathrm{Sc}$ & 96 & 27 & 16 & 42 & 104 & 103 \\
\hline $\mathrm{Y}$ & 778 & 205 & 1152 & 637 & 1457 & 127 \\
\hline $\mathrm{La}$ & 594 & 87 & 1260 & 193 & 1218 & 48 \\
\hline $\mathrm{Ce}$ & 1842 & 365 & 3562 & 696 & 4076 & 308 \\
\hline $\operatorname{Pr}$ & 244 & 40 & 412 & 103 & 473 & 27 \\
\hline $\mathrm{Nd}$ & 1025 & 167 & 1524 & 514 & 1879 & 130 \\
\hline $\mathrm{Sm}$ & 276 & 50 & 373 & 158 & 523 & 41 \\
\hline $\mathrm{Eu}$ & 42 & 10 & 52 & 26 & 77 & 9 \\
\hline $\mathrm{Gd}$ & 271 & 48 & 392 & 176 & 514 & 44 \\
\hline $\mathrm{Tb}$ & 39 & 9 & 56 & 29 & 78 & 6 \\
\hline Dy & 222 & 54 & 281 & 149 & 406 & 31 \\
\hline Ho & 38 & 10 & 45 & 25 & 72 & 6 \\
\hline Er & 89 & 27 & 106 & 61 & 164 & 17 \\
\hline $\mathrm{Tm}$ & 11 & 3 & 12 & 7 & 19 & 2 \\
\hline $\mathrm{Yb}$ & 53 & 17 & 80 & 40 & 97 & 13 \\
\hline $\mathrm{Lu}$ & 8 & 2 & 9 & 5 & 14 & 2 \\
\hline $\mathrm{LREE}_{\mathrm{N}} / \mathrm{HREE}_{\mathrm{N}}$ & 0.76 & 0.56 & 0.91 & 0.55 & 0.78 & 0.64 \\
\hline $\mathrm{La}_{\mathrm{N}} / \mathrm{Yb}_{\mathrm{N}}$ & 1.12 & 0.51 & 1.57 & 0.48 & 1.26 & 0.46 \\
\hline $\mathrm{La}_{\mathrm{N}} / \mathrm{Sm}_{\mathrm{N}}$ & 0.41 & 0.33 & 0.65 & 0.23 & 0.45 & 0.27 \\
\hline $\mathrm{Sm}_{\mathrm{N}} / \mathrm{Yb}_{\mathrm{N}}$ & 2.72 & 1.52 & 2.42 & 2.04 & 2.81 & 1.68 \\
\hline $\mathrm{Ce} / \mathrm{Ce} *$ & 1.20 & 1.50 & 1.24 & 1.18 & 1.33 & 1.89 \\
\hline $\mathrm{Eu} / \mathrm{Eu}^{*}$ & 0.78 & 0.86 & 0.73 & 0.78 & 0.76 & 1.13 \\
\hline
\end{tabular}

$\mathrm{Ce} / \mathrm{Ce}^{*}=\mathrm{Ce}_{\mathrm{N}} /\left(0.5 \mathrm{La}_{\mathrm{N}}+0.5 \operatorname{Pr}_{\mathrm{N}}\right)$

$\mathrm{Eu} / \mathrm{Eu}^{*}=\mathrm{Eu}_{\mathrm{N}} /\left(0.5 \mathrm{Sm}_{\mathrm{N}}+0.5 \mathrm{Dy}_{\mathrm{N}}\right)$ and 5\% for ICP-MS measurements. Certified solutions (CPI International-CCV standard 1-solution $\mathrm{A}$ ) and two AMD laboratory standards supplied by P. Verplank (USGS) were intercalated within the samples to check the analytical accuracy. The deviation from the recommended values was always lower than $5 \%$, with the exception of Eu, giving values $20 \%$ below the value reported by Verplanck et al. (2001). The ferrous and total dissolved iron concentrations in the initial AMD samples were determined by colorimetry in a UV-VIS HP spectrophotometer using the ferrozine method 


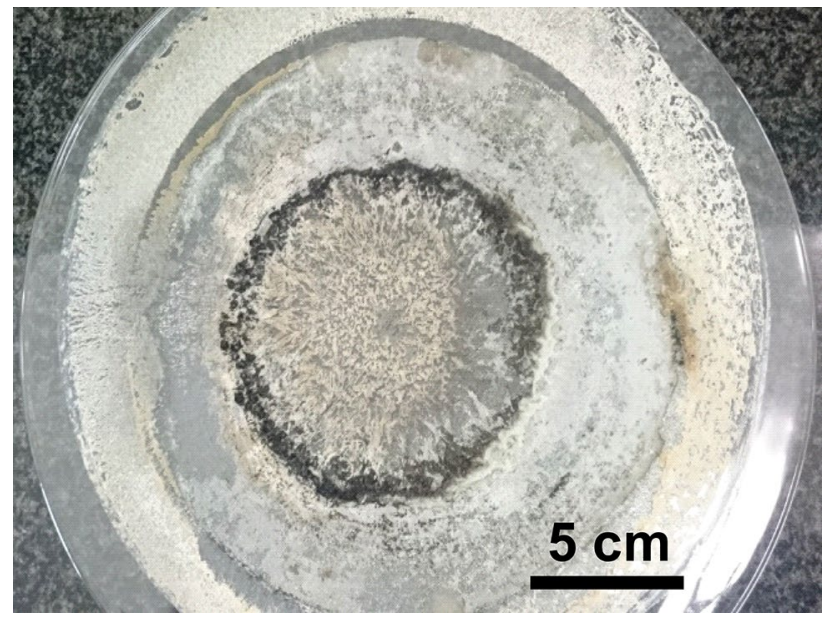

Fig. 1 Sulfates resulting from evaporation to dryness of AMD from the Poderosa mine

(To et al. 1999). The Fe(III) concentration was obtained as the difference between total iron (Fe(tot)) and $\mathrm{Fe}(\mathrm{II})$. The quality of the results was assured by measuring several standards, blanks and duplicates. The Fe(tot) concentrations matched the ICP-AES results within $10 \%$. All the mineralogical and chemical analyses were performed at the Institute of Environmental Assessment and Water Research, CSIC, Barcelona.

\section{Geochemical Modeling}

Geochemical calculations were performed with the PHREEQC code, version 3.6.2 (Parkhurst and Appelo, 1999) and the Pitzer ion-ion interaction approach. The ionion interaction parameters of the major solutes and solid equilibrium constants of their sulfates were extracted from Harvie et al. (1984), Reardon and Beckie (1987), Reardon (1988), Delany and Lundeen (1990) and Tosca et al. (2005). Calculations were performed at $25^{\circ} \mathrm{C}$, in equilibrium with the atmosphere and no additional constraints. The minerals were assumed to precipitate as the brine reached equilibrium. Although the solubility product of some REE hydrated sulfates $\left(\mathrm{REE}_{2}\left(\mathrm{SO}_{4}\right)_{3}: \mathrm{nH}_{2} \mathrm{O}, n=8\right.$ or 9$)$ is found in the existing literature (HSC Chemistry 2020), modeling the solubility of REE-sulfates was not possible due to the absence of the $\mathrm{REE}-\mathrm{SO}_{4}$ interaction parameters required for such high concentration sulfate brines.

\section{Statistical Analysis}

The statistical analysis was performed individually for each acid water sample, i.e. for the set of salts formed from the same initial water. Univariate statistics were used to check the Gaussian distribution of each element and bivariate statistical analysis (Pearson) was used as a preliminary inspection of correlation coefficients between the different major and trace elements. The statistical analysis was undertaken to unravel the attachment of the trace elements to the sulfate-forming major cations $(\mathrm{Ca}, \mathrm{Mg}, \mathrm{Fe}, \mathrm{Al})$; principal component analysis (PCA) was used to assign each element, particularly REE, to a major sulfate (Davis 2002). The PCs were listed according to their contribution to the variance and were generated with no correlation between them, i.e. they are orthogonal. A Varimax orthogonal rotation method was used to minimize the number of variables that have high loadings on each factor by giving those variables the maximum weight in the factor and minimum weight to the variables less correlated to the axis. The PCA was performed with SPSS software (https://www.ibm.com/es-es/products/ spss-statistics).

\section{Results and Discussion}

\section{Chemistry of the Initial AMD Samples}

The analyses of selected major and trace elements of the initial waters are listed in Table 1 . The complete analyses are reported in Table S-1 (supplemental information). The analytical values, normalized to the North American Shale Composite, NASC (Gromet et al. 1984), showed a depletion in LREEs with respect to HREEs with $\Sigma \mathrm{LREE}_{\mathrm{N}} / \Sigma \mathrm{HREE}_{\mathrm{N}}$ less than 1. The most distinctive characteristic of all the AMD samples was their enrichment in MREEs (from $\mathrm{Sm}$ to Dy), with $\mathrm{Sm}_{\mathrm{N}} / \mathrm{La}_{\mathrm{N}}$ and $\mathrm{Sm}_{\mathrm{N}} / \mathrm{Yb}_{\mathrm{N}}$ ratios clearly greater than 1. The enrichment in MREEs has been commonly described in many AMD samples (Gimeno et al. 2000; Johannesson and Zhou 1999; Ferreira da Silva et al. 2009; Romero et al. 2010; Sahoo et al. 2012). Most samples showed a negative anomaly in $\mathrm{Eu}$, with $\mathrm{Eu} / \mathrm{Eu}^{*}\left(\mathrm{Eu}^{*}=0.5 \mathrm{Sm}_{\mathrm{N}}+0.5 \mathrm{Dy}_{\mathrm{N}}\right)$ values distinctly less than 0.9 , with the exception of the Sabina sample, with a Eu/Eu* value of 1.13. Negative Eu anomalies have also been reported in areas with felsic igneous rocks (Ferreira da Silva et al. 2009; Leybourne and Johannesson 2008), and has been attributed to igneous differentiation processes (Fowler and Doig 1983). The Eu anomalies recorded here are consistent with the origin of the samples, most of them linked to felsic volcanic rocks of the northern IPB, whereas Sabina is located in the south of the province, which is dominated by sedimentary sequences. Interestingly, this sample also showed the highest proportion of Sc. Negative Ce anomalies, with $\mathrm{Ce} / \mathrm{Ce} *\left(\mathrm{Ce}^{*}=0.5 \mathrm{La}_{\mathrm{N}}+0.5 \mathrm{Pr}_{\mathrm{N}}\right)$ values less than 1 , were absent in the samples analyzed, indicating that oxidation of $\mathrm{Ce}$ (III) to $\mathrm{Ce}$ (IV) and the precipitation of $\mathrm{CeO}_{2}$ does not take place, probably due to the predominance of $\mathrm{Fe}(\mathrm{II})$ over $\mathrm{Fe}$ (III) (Bau 1999; Leybourne and Johannesson 2008). 


\section{Mineralogy of the Evaporitic Salts}

The mineralogy of the solid precipitates was mainly made up of gypsum, alunogen, $\mathrm{Mg}$ sulfates, and $\mathrm{Fe}(\mathrm{II})$ sulfates with different degrees of hydration (epsomite-hexahydrite-pentahydrite and melanterite-rozenite-szomolnokite) and two Fe(III) sulfates (copiapite and rhomboclase). The semi-quantitative proportions of these phases as deduced from XRD are listed in Table 2. These proportions are the average of five solid samples for each initial water and are only roughly coincident with the normative proportions deduced from the major cation constituents of the samples. In addition to these major phases, some minor amounts of other sulfates, such as gunningite, butlerite, jakoite, chalcantite, coquimbite, and halotrichitepickeringite, were also identified in the XRD spectra of some samples. The main mineralogy was coincident with the efflorescent salts reported in evaporated ponds from AMD environments (Hammarstrom et al. 2005; Jambor et al. 2000; Jerz et al. 1999) and from the IPB in particular (FernándezRemolar et al. 2005; Romero et al. 2006; Rull et al. 2014).

The inspection under FESEM-EDS revealed that the samples were formed by a mixture of mm-sized plate crystals of alunogen with aggregates of micron-sized crystals of Fe and/or Mg sulfates (Fig. 2). The Fe sulfates contained
Table 2 Mineral proportions (wt \%) obtained from XRD of the solid samples (average of five samples) resulting from evaporation. In brackets, the normative proportion of minerals as deduced from the AMD bulk analyses of Table 1

\begin{tabular}{llllll}
\hline SAMPLE & Gypsum & Alunogen & Mg sulfates & Fe(II) sulfates & Fe(III) sulfates \\
\hline Agrio & $4(2)$ & $58(69)$ & $29(22)$ & $3(3)$ & $5(3)$ \\
Esperanza & $14(5)$ & $42(52)$ & $19(17)$ & $25(22)$ & $0(5)$ \\
Monte Romero & $14(5)$ & $29(34)$ & $27(21)$ & $30(32)$ & $0(8)$ \\
Perrunal & $8(4)$ & $35(55)$ & $28(13)$ & $24(24)$ & $0(3)$ \\
Poderosa & $7(3)$ & $45(66)$ & $17(9)$ & $21(14)$ & $9(8)$ \\
Sabina & $2(1)$ & $64(65)$ & $15(3)$ & $25(26)$ & $0(5)$ \\
\hline
\end{tabular}

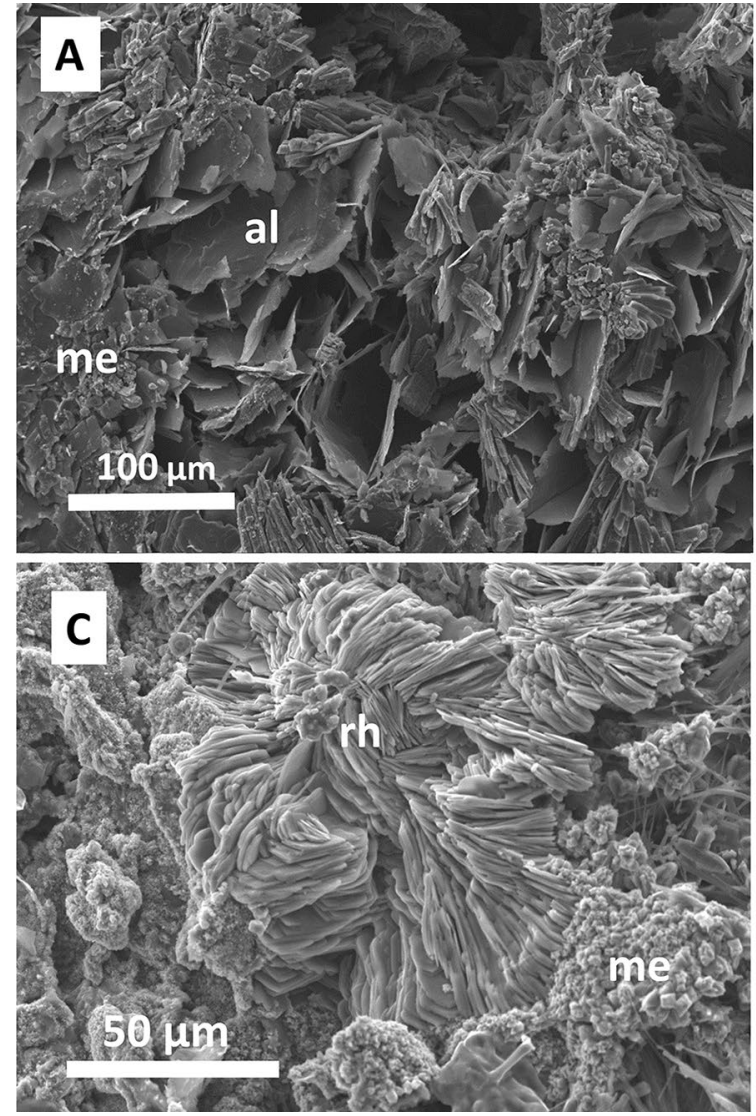

Fig. 2 A Platy crystals of alunogen (al) intergrown with aggregates of Fe sulfate crystals (me); B Needles of alunogen growing from platy crystals of the same mineral; $\mathbf{C}$ Aggregates of platy crystals of rhom-
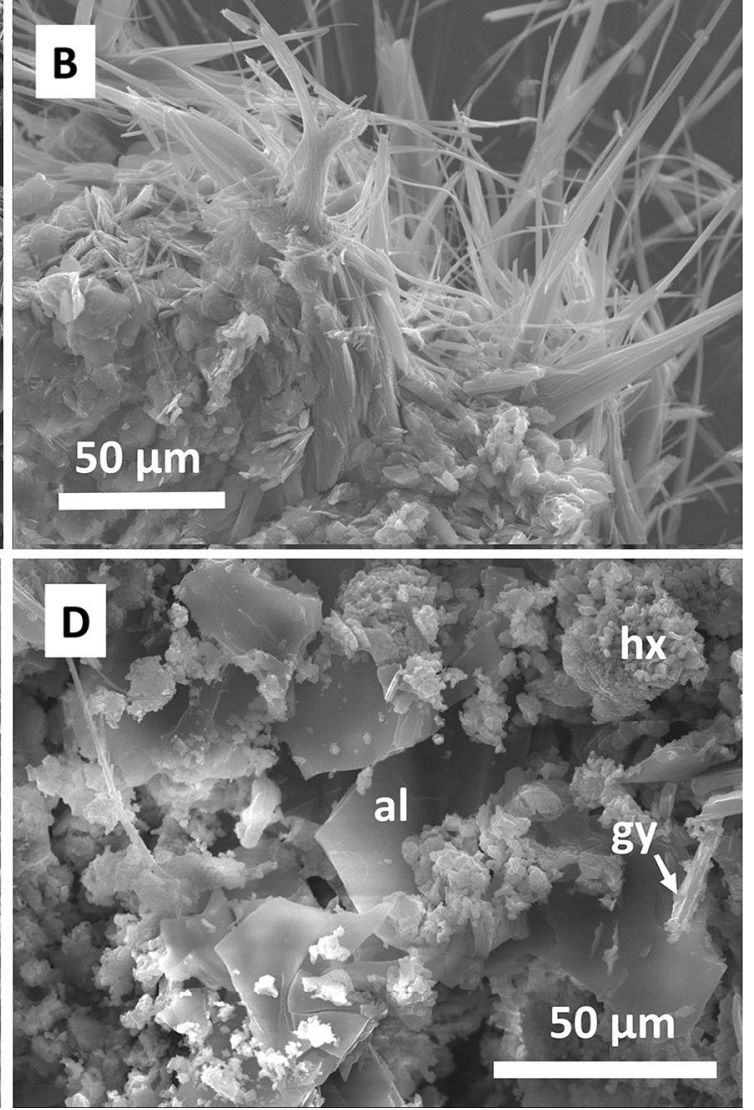

boclase (rh) and Fe sulfates (me); D Mixture of platy crystals of alunogen (al) with aggregates of $\mathrm{Mg}$ sulfates (hx) and elongated crystals of gypsum (gy) 
minor and variable amounts of $\mathrm{Mg}, \mathrm{Cu}, \mathrm{Zn}$, and $\mathrm{Mn}$, and the $\mathrm{Mg}$ sulfates could also contain $\mathrm{Fe}, \mathrm{Zn}, \mathrm{Cu}, \mathrm{Co}$, and $\mathrm{Mn}$. The presence of these minor elements has already been described (Hammarstrom et al. 2005; Jambor et al. 2000). The copiapite contained variable proportions of $\mathrm{Mg}, \mathrm{Al}$, and $\mathrm{Fe}$, whereas alunogen only showed minor amounts of $\mathrm{Si}$ and $\mathrm{Fe}$; no elements other than $\mathrm{Ca}$ and $\mathrm{S}$ were detected in the gypsum.

Despite the concentric appearance (Fig. 1), no clear zonation was observed in the minerals from the border to the center of the watch glass in any of the samples. Thus, the same major minerals were present in the XRD observations of samples from practically all the rings. Moreover, all the minerals seem to precipitate simultaneously and no textures indicating a clear mineral sequence were observed under FESEM-EDS inspection (Fig. 2). Only the halotrichite-pickeringite needles appeared to form later on the surface of the rest of the minerals, as already described by Hammarstrom et al. (2005).

The lack of zonation contradicts the expected mineral sequence of precipitation according to their increasing solubility. Thus, gypsum was expected to precipitate first, followed by copiapite, melanterite, hexahydrite, or alunogen depending on the composition of the original AMD (supplemental Fig. S-1). Discrepancies between the predicted and observed sequences of precipitation have also been described by Moncur et al. (2015), Ptacek and Blowes (2000), and Basallote et al. (2019). A possible reason could be that the observed minerals are not pure phases. Ideal solid solutions with very close end-member solubility, such as $\mathrm{Fe}(\mathrm{II})$ and $\mathrm{Mg}$ sulfates, will have a lower solubility than pure members (Glynn 2000). However, the drop in solubility will be at most half that of the pure end members and, therefore, it would not justify the precipitation of $\mathrm{Fe}$ and $\mathrm{Mg}$ sulfates with gypsum in the outer rings. Another reason for discrepancies would be the existence of volumes of remaining brine trapped among the growing crystals (Moncur et al. 2015). This could justify the absence of clear zonation in the studied samples. The absence of the less soluble gypsum in some outer rings could also be due to lack of detection by XRD $(<5 \%)$ or to the inhibition of its nucleation caused by other concentrated solutes.

\section{Chemical Analysis of Evaporitic Salts}

A summary of the analyses of the solids precipitated for each initial water sample is shown in Table 3, while the complete analysis of all the solid samples is shown in Table S-1. Table S-1 is sequentially ordered from the border to the center of the watch glass. No evolution of the major element concentration can be observed, confirming the lack of clear concentric mineral zonation. As expected from evaporation in a closed system, analyses of the solids may preserve the main trends of the REE distribution described for the original water. Thus, the NASC-normalized REE patterns also show a depletion in LREEs, an enrichment in MREEs (from Sm to Dy), with respect to LREEs and HREEs, and positive and negative anomalies in $\mathrm{Ce}$ and $\mathrm{Eu}$, respectively (Table 3, supplemental Fig. S-2).

\section{Statistical Analysis}

For each initial AMD evaporated, between 20 and 33 salt samples were obtained. For each salt analysis, a set of 46 elements was initially available (Table S1). Therefore, a reduction in the number of elements was needed prior to any significant multivariate statistics. First, elements with all or part of the concentrations below the detection limit, such as $\mathrm{B}, \mathrm{K}$ and $\mathrm{P}$, were not considered to prevent their overestimation (Yong and Pearce 2013). Then, the univariate Shapiro-Wilk test allowed us to discard those elements, such as $\mathrm{Ba}, \mathrm{Be}, \mathrm{Cr}, \mathrm{Pb}$ and $\mathrm{Rb}$, that did not show a normal distribution $(\mathrm{p}<0.50)$. Nevertheless, the number of variables (38) could seem excessive with respect to the number of samples (20-33). However, the bivariate analysis showed groups of elements with very strong correlation in all the sets of analyses that could be considered lumped variables in multivariate analysis. Thus, LREEs (from La to Gd), HREEs (from Dy to $\mathrm{Lu}$ and $\mathrm{Y}$ ) and $\mathrm{Mg}-\mathrm{Zn}-\mathrm{Co}-\mathrm{Ni}$ form three compact groups with Pearson coefficients higher than 0.9. Then, the procedure to decrease the number of variables was to substitute very similar elements (for example, LREE) by a single one until the set fulfilled the tests for data adequacy, i.e. non-null determinant, Bartlett's test of sphericity with $p<0.05$ and Kaiser-Meyer-Olkin index above 0.5 (Yong and Pearce, 2013). On observing the results of the different runs, the same number of principal components (PC) and the contribution to the PC loading of each considered element were practically identical regardless of the removed elements. Therefore, for simplicity only the results of the runs with all the elements will be shown and discussed, although they did not respect the data adequacy indices.

The PCA results for the six sets of precipitated sulfates are plotted in Fig. 3 for REE elements and in Fig. 4 for the rest of the elements. The numerical values of the PCA are listed in Table S-2. In all cases, only three PCs were able to explain more than $80 \%$ of the variance of the samples and always grouped the same elements: $\mathrm{PC} 1) \mathrm{Ca}, \mathrm{Sr}$, and LREEs; PC2) HREEs; and PC3) $\mathrm{Mg}, \mathrm{Fe}, \mathrm{Co}, \mathrm{Cu}, \mathrm{Mn}, \mathrm{Ni}$, and $\mathrm{Zn}$.

The systematic presence of $\mathrm{Ca}$ indicates that PC1 may group the elements included in gypsum. Strontium commonly replaces $\mathrm{Ca}$ in gypsum and anhydrite (Denison et al. 1998; Feldmann and Demopoulos 2013). With respect to 
Table 3 Average chemical composition of the solid samples obtained from evaporation experiments

\begin{tabular}{|c|c|c|c|c|c|c|c|c|c|c|c|c|}
\hline \multirow[t]{3}{*}{$\mathrm{N}$ samples } & \multirow{2}{*}{\multicolumn{2}{|c|}{$\frac{\text { Agrio }}{33}$}} & \multirow{2}{*}{\multicolumn{2}{|c|}{$\frac{\text { Esperanza }}{20}$}} & \multirow{2}{*}{\multicolumn{2}{|c|}{$\frac{\text { Monte-Romero }}{21}$}} & \multirow{2}{*}{\multicolumn{2}{|c|}{$\frac{\text { Perrunal }}{21}$}} & \multirow{2}{*}{\multicolumn{2}{|c|}{$\frac{\text { Poderosa }}{23}$}} & \multirow{2}{*}{\multicolumn{2}{|c|}{$\frac{\text { Sabina }}{22}$}} \\
\hline & & & & & & & & & & & & \\
\hline & Average & st.dev & Average & st.dev & Average & st.dev & Average & st.dev & Average & st.dev & Average & st.dev \\
\hline \multicolumn{13}{|l|}{$\mathrm{mg} / \mathrm{L}$} \\
\hline $\mathrm{Al}$ & 69.9 & 6.4 & 31.7 & 3.4 & 28.3 & 3.7 & 32.0 & 4.8 & 29.0 & 4.6 & 40.2 & 6.6 \\
\hline $\mathrm{Ca}$ & 27.0 & 10.6 & 24.9 & 8.1 & 46.4 & 10.3 & 20.8 & 4.1 & 12.4 & 3.4 & 4.5 & 1.4 \\
\hline $\mathrm{Cu}$ & 5.4 & 0.7 & 3.6 & 0.5 & 1.4 & 0.1 & 1.7 & 0.2 & 10.7 & 1.4 & 15.2 & 1.5 \\
\hline $\mathrm{Fe}$ & 47.8 & 6.9 & 74.8 & 7.8 & 178.8 & 19.6 & 94.0 & 9.9 & 135.8 & 16.6 & 87.4 & 10.3 \\
\hline $\mathrm{K}$ & 0.7 & 0.2 & 1.3 & 1.9 & 0.8 & 0.2 & $<0.5$ & & 1.8 & 0.8 & 1.4 & 1.0 \\
\hline $\mathrm{Mg}$ & 79.3 & 8.1 & 36.4 & 3.7 & 75.0 & 7.7 & 35.3 & 2.2 & 14.5 & 1.6 & 7.4 & 0.6 \\
\hline $\mathrm{Mn}$ & 7.3 & 1.2 & 1.9 & 0.2 & 9.9 & 0.7 & 12.1 & 0.8 & 0.5 & 0.1 & 1.4 & 0.2 \\
\hline $\mathrm{Na}$ & 1.6 & 0.4 & 4.3 & 0.8 & 6.7 & 0.9 & 3.4 & 0.7 & 1.9 & 0.6 & 3.0 & 1.4 \\
\hline $\mathrm{S}$ & 298.9 & 17.2 & 184.9 & 15.8 & 352.1 & 30.6 & 192.4 & 10.7 & 177.8 & 16.7 & 205.6 & 22.6 \\
\hline $\mathrm{Si}$ & 1.3 & 0.5 & 1.4 & 0.5 & 1.9 & 0.6 & 1.9 & 0.5 & 2.0 & 0.6 & 0.9 & 0.6 \\
\hline $\mathrm{Zn}$ & 13.4 & 1.4 & 4.1 & 0.5 & 91.9 & 9.3 & 4.5 & 0.2 & 8.3 & 1.0 & 0.9 & 0.1 \\
\hline \multicolumn{13}{|l|}{$\mu \mathrm{g} / \mathrm{L}$} \\
\hline $\mathrm{Sc}$ & 8.7 & 1.3 & 4.0 & 0.7 & 1.3 & 0.2 & 2.2 & 0.5 & 7.0 & 0.8 & 7.6 & 1.2 \\
\hline $\mathrm{Y}$ & 52.4 & 4.3 & 39.1 & 4.6 & 153.4 & 14.1 & 41.5 & 7.7 & 143.6 & 20.8 & 9.6 & 1.4 \\
\hline $\mathrm{La}$ & 36.6 & 6.3 & 12.9 & 1.9 & 205.9 & 20.1 & 14.2 & 1.1 & 113.5 & 19.1 & 2.9 & 0.6 \\
\hline $\mathrm{Ce}$ & 139.9 & 30.9 & 52.8 & 10.3 & 533.3 & 39.2 & 64.4 & 6.2 & 440.6 & 80.6 & 20.0 & 4.1 \\
\hline $\operatorname{Pr}$ & 16.6 & 3.9 & 6.4 & 1.2 & 58.8 & 6.6 & 7.8 & 0.8 & 41.3 & 7.8 & 1.9 & 0.4 \\
\hline $\mathrm{Nd}$ & 66.9 & 15.9 & 25.5 & 5.2 & 206.7 & 23.4 & 35.9 & 3.6 & 154.6 & 28.6 & 8.7 & 1.9 \\
\hline $\mathrm{Sm}$ & 20.5 & 4.4 & 8.6 & 1.6 & 58.7 & 6.0 & 12.9 & 1.2 & 48.8 & 8.5 & 2.9 & 0.6 \\
\hline $\mathrm{Eu}$ & 3.2 & 0.6 & 1.6 & 0.2 & 9.1 & 0.9 & 2.2 & 0.2 & 6.8 & 1.1 & 0.6 & 0.1 \\
\hline $\mathrm{Gd}$ & 21.7 & 3.1 & 8.1 & 1.2 & 70.0 & 6.7 & 14.7 & 1.2 & 53.5 & 8.1 & 3.1 & 0.6 \\
\hline $\mathrm{Tb}$ & 3.1 & 0.4 & 1.8 & 0.2 & 9.2 & 1.1 & 2.3 & 0.2 & 8.0 & 1.2 & 0.4 & 0.1 \\
\hline Dy & 15.7 & 1.3 & 10.0 & 1.2 & 44.1 & 4.8 & 11.6 & 1.3 & 39.0 & 5.6 & 2.4 & 0.4 \\
\hline Ho & 3.1 & 0.2 & 2.1 & 0.2 & 7.8 & 0.8 & 2.1 & 0.2 & 7.1 & 1.1 & 0.5 & 0.1 \\
\hline $\mathrm{Er}$ & 6.6 & 0.6 & 5.3 & 0.6 & 18.5 & 1.7 & 5.2 & 0.6 & 17.2 & 2.6 & 1.4 & 0.2 \\
\hline $\mathrm{Tm}$ & 0.8 & 0.1 & 0.7 & 0.1 & 2.2 & 0.2 & 0.6 & 0.1 & 2.0 & 0.3 & 0.2 & 0.0 \\
\hline $\mathrm{Yb}$ & 4.4 & 0.4 & 3.6 & 0.5 & 10.9 & 0.9 & 3.3 & 0.4 & 9.9 & 1.5 & 1.1 & 0.1 \\
\hline $\mathrm{Lu}$ & 0.7 & 0.1 & 0.5 & 0.1 & 1.4 & 0.1 & 0.5 & 0.1 & 1.3 & 0.2 & 0.2 & 0.0 \\
\hline $\operatorname{LREE}_{\mathrm{N}} / \mathrm{HREE}_{\mathrm{N}}$ & 0.69 & 0.11 & 0.45 & 0.06 & 0.83 & 0.04 & 0.53 & 0.05 & 0.71 & 0.06 & 0.54 & 0.04 \\
\hline $\mathrm{La}_{\mathrm{N}} / \mathrm{Yb}_{\mathrm{N}}$ & 0.84 & 0.16 & 0.37 & 0.06 & 1.89 & 0.16 & 0.44 & 0.05 & 1.14 & 0.09 & 0.28 & 0.03 \\
\hline $\mathrm{La}_{\mathrm{N}} / \mathrm{Sm}_{\mathrm{N}}$ & 0.35 & 0.02 & 0.29 & 0.02 & 0.68 & 0.02 & 0.21 & 0.01 & 0.45 & 0.01 & 0.20 & 0.01 \\
\hline $\mathrm{Sm}_{\mathrm{N}} / \mathrm{Yb}_{\mathrm{N}}$ & 2.46 & 0.57 & 1.27 & 0.25 & 2.81 & 0.26 & 2.08 & 0.30 & 2.54 & 0.26 & 1.41 & 0.18 \\
\hline $\mathrm{Ce} / \mathrm{Ce}^{*}$ & 1.39 & 0.05 & 1.41 & 0.06 & 1.22 & 0.06 & 1.46 & 0.02 & 1.60 & 0.03 & 1.96 & 0.03 \\
\hline $\mathrm{Eu} / \mathrm{Eu}^{*}$ & 0.80 & 0.04 & 0.79 & 0.04 & 0.82 & 0.02 & 0.85 & 0.04 & 0.71 & 0.02 & 1.03 & 0.04 \\
\hline
\end{tabular}

$\mathrm{Ce} / \mathrm{Ce}^{*}=\mathrm{Ce}_{\mathrm{N}} /\left(0.5 \mathrm{La}_{\mathrm{N}}+0.5 \mathrm{Pr}_{\mathrm{N}}\right)$

$\mathrm{Eu} / \mathrm{Eu}^{*}=\mathrm{Eu}_{\mathrm{N}} /\left(0.5 \mathrm{Sm}_{\mathrm{N}}+0.5 \mathrm{Dy}_{\mathrm{N}}\right)$

LREEs, the extension of this group depended on each sample, including some HREEs. Thus, PC1 contained REEs from $\mathrm{La}$ to $\mathrm{Tb}$ in Perrunal and Poderosa, from La to Dy in Esperanza, from La to Ho in Agrio and Monte Romero, and from $\mathrm{La}$ to $\mathrm{Tm}-\mathrm{Y}$ in Sabina.

PC2 was formed by a variable group of HREEs (including Y), complementary to that described for PC1. However, the assignment adsorption of the PC2 elements by a major sulfate was not clear. Thus, PC2 included Al in Sabina and Perrunal, $\mathrm{Fe}$ in Agrio, $\mathrm{Al}+\mathrm{Mg}+\mathrm{Fe}$ in Poderosa, and none of them in Esperanza and Monte Romero (see the numerical PCA results in Table S-2).

Finally, PC3 was formed by $\mathrm{Mg}, \mathrm{Fe}, \mathrm{Co}, \mathrm{Cu}, \mathrm{Mn}, \mathrm{Ni}$, and $\mathrm{Zn}$ in the six sets of samples analyzed. This group would correspond to $\mathrm{Mg}$ - $\mathrm{Fe}$ (II) sulfates with trace metals with charges and radii similar to those of $\mathrm{Mg}$ and $\mathrm{Fe}(\mathrm{II})$. 


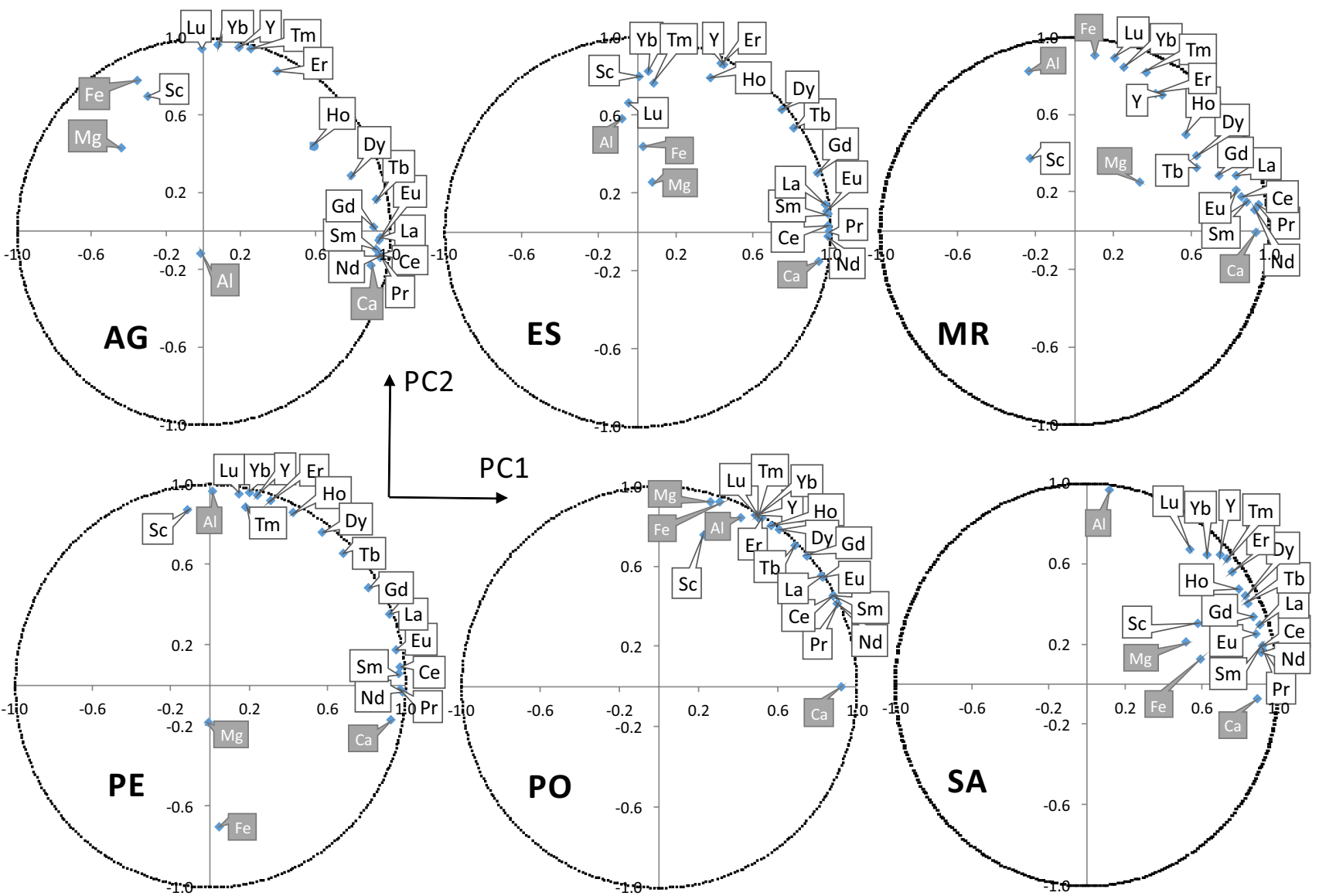

Fig. 3 PC1-PC2 plot of correlation loading for the REE together with the major components of sulfates (Al, $\mathrm{Ca}, \mathrm{Fe}$ and $\mathrm{Mg}$ ) for the six sets of evaporite samples. Legend: AG Agrio, ES Esperanza, MR Monte Romero, PE Perrunal, PO Poderosa, SA Sabina

This close association is consistent with the observations of FESEM-EDS, where the peaks of these trace metals were commonly observed in many EDS spectra of the $\mathrm{Fe}(\mathrm{II})$ and $\mathrm{Mg}$ sulfates. Moreover, these elements have also been extensively reported in efflorescent salts from AMD settings (Alpers et al. 1994; Hammarstrom et al. 2005; Jambor et al. 2000; Romero et al. 2006).

Due to its economic value, special attention has been given to Sc. In contrast to the rest of the REEs, Sc did not show a clear association with any of the three PCs identified (Fig. 3; Table S-2). Thus, Sc appeared to be associated with PC1 in SA, with PC2 in AG, ES, PE, and PO, and independent from the three PCs in MR. According to Shannon (1976), the ionic radius of Sc in eight coordinates $(1.01 \mathrm{~A})$ is smaller than the rest of the REEs and very different from that of $\mathrm{Ca}(1.26 \mathrm{~A})$, which could prevent its preferential inclusion in the gypsum structure. Despite its ionic radius being similar to that of $\mathrm{Mg}$ in octahedral sites ( 0.885 and $0.86 \mathrm{~A}$, respectively), Sc did not show any association with PC3, probably due to their different charges. Unlike gypsum, Mg sulfates only accept divalent metals in octahedral coordination.
Some trace elements, such as $\mathrm{Cd}, \mathrm{Na}, \mathrm{S}, \mathrm{Si}$, Th, Tl, and U, did not show any persistent association with any component in more than two of the PCAs of the six samples analyzed, and tended to plot towards the center of the PC diagrams (Fig. 4). In contrast, As, Ga, Ge, and Se seemed to form an association related to PC1 in ES, MR, and PO, but this was less clear in the rest of the samples. This common grouping may be due to the close similarity of the ionic radii of $\mathrm{As}(\mathrm{III}), \mathrm{Ga}(\mathrm{III}), \mathrm{Ge}(\mathrm{IV})$, and $\mathrm{Se}(\mathrm{IV})$ in octahedral coordination (Shannon 1976). The lack of a constant correlation of $\mathrm{S}$ with major and trace elements is obvious, as sulfates are the solid phases that contribute to the three PCs. The lack of a relationship between $\mathrm{Si}$ and $\mathrm{Al}$ seems to contradict the FESEM-EDS observation of the presence of Si in many samples of Al sulfate and suggests major Si precipitation as an independent amorphous phase. Indeed, the six initial acidic waters were already saturated in amorphous silica prior to evaporation.

Looking into the details of $\mathrm{PC} 1$ and $\mathrm{PC} 2$, there was a systematic distribution of REEs with respect to $\mathrm{Ca}$. Thus, LREEs, particularly $\mathrm{Pr}$ and $\mathrm{Nd}$, were closer to $\mathrm{Ca}$ in all plots in Fig. 3, whereas $\mathrm{La}, \mathrm{Ce}$, the rest of the LREEs and 


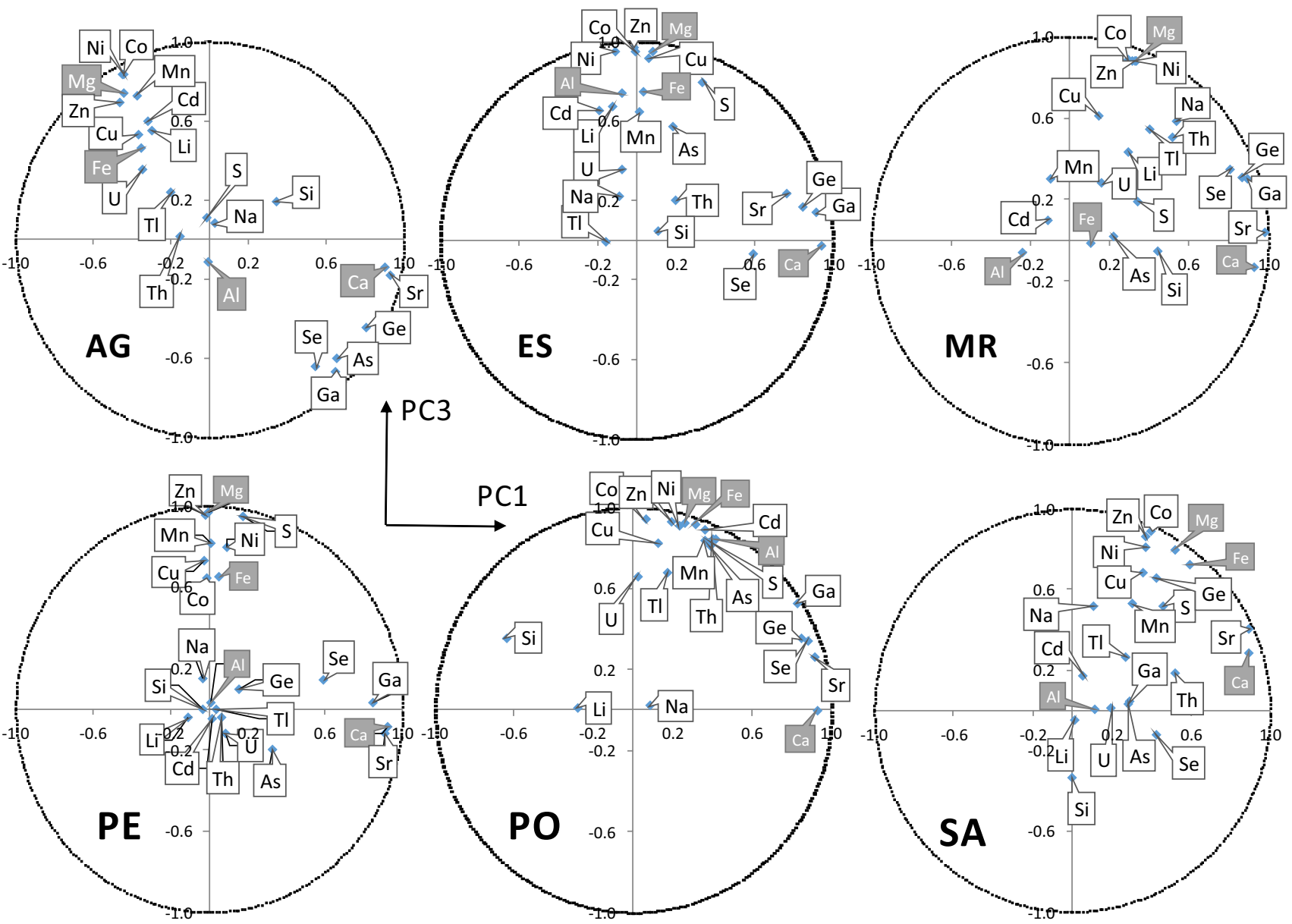

Fig. 4 PC1-PC3 plot of correlation loadings for the rest of the elements together with the major components of sulfates (Al, Ca, Fe and $\mathrm{Mg}$ ) for the six sets of evaporite samples. Legend: $A G$ Agrio, ES Esperanza, $M R$ Monte Romero, PE Perrunal, PO Poderosa, SA Sabina

the HREEs plotted progressively away. This REE distribution is clearly related to the eight-fold coordination of $\mathrm{Ca}$ in gypsum, as evidenced by the high correlation $\left(\mathrm{R}^{2}>0.83\right)$ between the Ca-REE Pearson coefficients and the difference in their ionic radius (Fig. 5), i.e. the closer the REE ionic radius is to that of $\mathrm{Ca}$, the higher the Pearson coefficient between them. Plots very similar to Fig. 5 can be obtained by substituting the binary correlation for the PCA proximity factor $r$ calculated as follows:

$r_{12}=h_{1} h_{2} \cos \alpha_{12}$

where $h$ is the length of the vectors representing each point in the plot and $\alpha$ is the angle between them. The high correlation strongly suggests that LREEs replaced $\mathrm{Ca}$ in the gypsum structure. The incorporation of lanthanides into gypsum has also been described by Inguaggiato et al. (2018) in acidic sulfate-rich brines from the Poas Volcano crater in Costa Rica, who also described a preferential incorporation of LREEs with respect to HREEs. X-ray computed tomography imaging of gypsum precipitated from the acidic waters of the Poas volcano in Costa Rica showed a higher accumulation of REEs in the outer part of the crystal. Based on this observation, these authors proposed that, rather than structural substitution, surface processes could be responsible for REE removal from water. However, due to the low $\mathrm{pH}$ values of the evaporating brines during sulfate precipitation, it is difficult for the predominant aqueous species $\mathrm{REESO}_{4}{ }^{+}$to reach highly protonated solid surfaces (Lozano et al. 2019a, b). If the gypsum crystal grew during progressive evaporation, REEs (and other metals) could concentrate in the residual brine, resulting in an enrichment of trace elements in the outermost layers.

Figure 5 displays a systematic deviation of the REE plots with respect to the theoretical linear correlation. Thus, $\mathrm{La}$ to Nd tend to show underestimation of the binary correlation, whereas $\mathrm{Sm}$ to $\mathrm{Tb}$ plots always show overestimation, and Dy to Tm show over to underestimations depending on the sample, and $\mathrm{Y}, \mathrm{Yb}$ and Lu plots always show underestimation (Fig. 5). A possible explanation of this distribution 

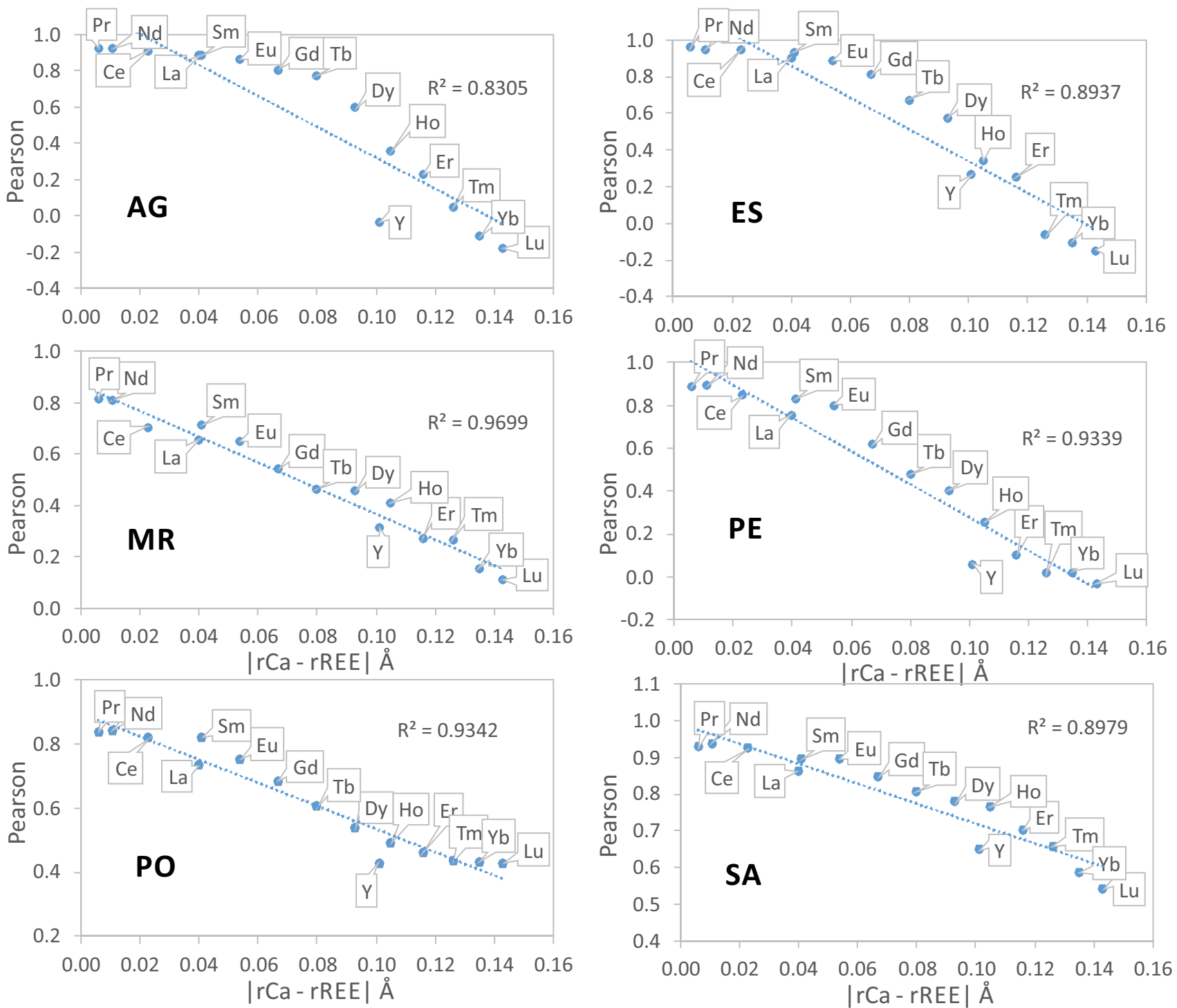

Fig. 5 Plot of REE-Ca Pearson binary correlations (Sc excluded) and the difference of the REE ionic radii with Ca in eight-fold coordination. Legend: $A G$ Agrio, ES Esperanza, $M R$ Monte Romero, PE Perrunal, PO Poderosa, SA Sabina

could be related to variations of the third ionization energies with the atomic number of the lanthanides, described as the "tetrad" effect (McLennan 1994), which can be better shown by removing the element labels in Fig. 5 (see supplemental Fig. S-3).

Despite the linear correlation between $\mathrm{Ca}$ and the lanthanides shown in Fig. 5, the absolute values of Pearson coefficients from $\mathrm{Tb}$ to Lu were very low $(<0.5)$ or even negative for $\mathrm{Yb}$ and $\mathrm{Lu}$ in some samples. The poor correlation with $\mathrm{Ca}$, together with the existence of a clearly identified PC2 in the six samples studied, suggests that in addition to gypsum, some other mineral(s) could also be affecting the REE distribution. Among them, $\mathrm{Al}, \mathrm{Mg}$, and Fe sulfates are the first candidates to be discussed.
In contrast to $\mathrm{Ca}$ in gypsum, $\mathrm{Al}, \mathrm{Mg}$, and Fe occupy sites of octahedral coordination in their sulfate structures. Then, the Pearson coefficients between REE and $\mathrm{Al}, \mathrm{Mg}$, and $\mathrm{Fe}$ were also compared with the differences in their ionic radii in octahedral sites. Correlations were poorer and less persistent than those shown by Ca. Thus, Al-HREE only exhibited significant Pearson coefficients $(>0.6)$ and increased with decreasing differences in their ionic radius in ES, PE, PO, and SA (supplemental Fig. S-4), whereas $\mathrm{Mg}$ and Fe did so only in ES and PO (Fig. S-5). Moreover, whereas differences in ionic radii between LREEs and $\mathrm{Ca}$ in eight-fold coordination were always less than $10 \%$, these differences in the case of HREEs and $\mathrm{Mg}, \mathrm{Fe}$ (both $\mathrm{Fe}^{3+}$ and $\mathrm{Fe}^{2+}$ ), and $\mathrm{Al}$ in octahedral coordination were always between 40 and 50\% (Shannon 1976). Such great differences in size would prevent a 
significant incorporation of HREEs in the octahedral sites of the $\mathrm{Al}, \mathrm{Mg}$, and $\mathrm{Fe}$ sulfates and suggest that HREEs would necessarily form an independent mineral. This would also be supported by the lack of contribution of $\mathrm{Al}, \mathrm{Mg}$, or $\mathrm{Fe}$ in PC2 in the multicomponent statistical analysis. Therefore, the good correlation between Pearson coefficients and ionic radii shown by some samples (Fig. S-4 and S-5) could be due to the coexistence of $\mathrm{Al}, \mathrm{Mg}$, and $\mathrm{Fe}$ with HREEs in the residual brine, caused by their concomitant exclusion from the gypsum formation.

\section{Selective Dissolution of Salts}

To confirm the inclusion of LREEs in gypsum and check the attachment of HREEs to other sulfates, the major sulfates were isolated by selective dissolution of the others. Table 4 contains the analyses of the residual solids from dissolution of six aliquots of the salts from AG water evaporation with Milli-Q water and five solutions saturated in gypsum, alunogen, hexahydrite, rozenite, and rhomboclase (labeled with $-\mathrm{s}$ ). Moreover, Table 4 also includes the analyses of

Table 4 Average chemical composition $(n=3)$ of the water and residual solid samples obtained from dissolution of evaporite salts with some sulfate-saturated waters. Original Agrio AMD sample

AMD $\quad$ salt + mQ-w salt+gy-w gypsum-s alunogen-s hexahy-s rozenite-s rhomb-s $\left[\begin{array}{llllll}\text { REE } & \text { Eff } & K_{\text {gy }} & K_{D}(g y)\end{array}\right.$

\begin{tabular}{|c|c|c|c|c|c|c|c|c|c|c|c|}
\hline $\mathrm{Al}$ & 1059 & 255 & 256 & 0.1 & 353 & 2.6 & 1.5 & 0.5 & & & \\
\hline $\mathrm{Ca}$ & 376 & 90 & 602 & 150 & 1.1 & 1.5 & 0.5 & 0.0 & & & \\
\hline $\mathrm{Cu}$ & 73 & 16 & 15 & 0.0 & 0.5 & 0.7 & 0.3 & 0.0 & & & \\
\hline $\mathrm{Fe}$ & 713 & 178 & 183 & 0.5 & 10.1 & 10.6 & 310 & 17.7 & & & \\
\hline $\mathrm{K}$ & 2.4 & 0.6 & 0.8 & $<0.5$ & $<0.5$ & $<0.5$ & $<0.5$ & $<0.5$ & & & \\
\hline $\mathrm{Mg}$ & 1040 & 258 & 274 & 0.5 & 1.1 & 724 & 0.5 & $<0.05$ & & & \\
\hline $\mathrm{Mn}$ & 96 & 20 & 21 & $<0.05$ & $<0.05$ & $<0.05$ & 0.4 & 0.1 & & & \\
\hline $\mathrm{Na}$ & 20 & 5.1 & 4.9 & 1.0 & 2.5 & 0.8 & 0.7 & 0.8 & & & \\
\hline $\mathrm{S}$ & 3922 & 988 & 1428 & 133 & 638 & 995 & 196 & 19 & & & \\
\hline $\mathrm{Si}$ & 41 & 5.8 & 1.0 & 4.8 & 3.6 & 1.8 & 1.1 & 0.8 & & & \\
\hline $\mathrm{Zn}$ & 191 & 43 & 41 & 0.0 & 0.6 & 0.6 & 0.3 & 0.0 & & & \\
\hline$\mu \mathrm{g} / \mathrm{L}$ & & & & & & & & & $\mathrm{mg} / \mathrm{kg}$ & $(\%)$ & $(\mathrm{kg} / \mathrm{L})$ \\
\hline $\mathrm{Sc}$ & 96 & 34 & 33 & 1 & $<0.8$ & $<0.8$ & $<0.8$ & $<0.8$ & $<0.1$ & $<0.6$ & 10 \\
\hline $\mathrm{Y}$ & 578 & 859 & 737 & 133 & 10.5 & 13.4 & 5.6 & $<0.8$ & 207 & 9.2 & 279 \\
\hline $\mathrm{La}$ & 634 & 682 & 539 & 175 & 7.2 & 10.8 & 4.1 & $<0.8$ & 269 & 15.3 & 516 \\
\hline $\mathrm{Ce}$ & 2242 & 2180 & 1560 & 573 & 21.6 & 30.2 & 11.4 & 0.86 & 881 & 16.0 & 595 \\
\hline $\operatorname{Pr}$ & 184 & 293 & 201 & 78 & 2.9 & 4.0 & 1.5 & $<0.8$ & 120 & 16.3 & 630 \\
\hline $\mathrm{Nd}$ & 775 & 1222 & 866 & 352 & 12.7 & 17.7 & 6.5 & $<0.8$ & 541 & 17.4 & 667 \\
\hline $\mathrm{Sm}$ & 226 & 327 & 233 & 87 & 3.2 & 4.6 & 1.7 & $<0.8$ & 134 & 16.2 & 614 \\
\hline $\mathrm{Eu}$ & 42 & 50 & 35 & 11 & $<0.8$ & $<0.8$ & $<0.8$ & $<0.8$ & 17 & 13.8 & 529 \\
\hline $\mathrm{Gd}$ & 251 & 314 & 240 & 74 & 3.3 & 4.5 & 1.8 & $<0.8$ & 114 & 14.2 & 494 \\
\hline $\mathrm{Tb}$ & 37 & 44 & 35 & 9 & $<0.8$ & $<0.8$ & $<0.8$ & $<0.8$ & 14 & 12.6 & 419 \\
\hline Dy & 222 & 248 & 194 & 44 & 2.5 & 3.2 & 1.3 & $<0.8$ & 68 & 10.9 & 358 \\
\hline Ho & 43 & 42 & 32 & 6 & $<0.8$ & $<0.8$ & $<0.8$ & $<0.8$ & 10 & 9.2 & 305 \\
\hline $\mathrm{Er}$ & 111 & 99 & 77 & 15 & 1.0 & 1.2 & $<0.8$ & $<0.8$ & 23 & 9.2 & 300 \\
\hline $\mathrm{Tm}$ & 15 & 12 & 9 & 2 & $<0.8$ & $<0.8$ & $<0.8$ & $<0.8$ & 2 & 8.0 & 271 \\
\hline $\mathrm{Yb}$ & 83 & 60 & 46 & 9 & $<0.8$ & 0.9 & $<0.8$ & $<0.8$ & 13 & 8.7 & 286 \\
\hline $\mathrm{Lu}$ & 12 & 8 & 6 & 1 & $<0.8$ & $<0.8$ & $<0.8$ & $<0.8$ & 2 & 7.5 & 253 \\
\hline $\mathrm{LREE}_{\mathrm{N}} / \mathrm{HREE}_{\mathrm{N}}$ & 0.76 & 0.80 & 0.75 & 1.15 & & & & & & & \\
\hline $\mathrm{La}_{\mathrm{N}} / \mathrm{Yb}_{\mathrm{N}}$ & 1.12 & 1.15 & 1.16 & 2.02 & & & & & & & \\
\hline $\mathrm{La}_{\mathrm{N}} / \mathrm{Sm}_{\mathrm{N}}$ & 0.41 & 0.40 & 0.44 & 0.39 & 0.43 & 0.45 & 0.46 & & & & \\
\hline $\mathrm{Sm}_{\mathrm{N}} / \mathrm{Yb}_{\mathrm{N}}$ & 2.72 & 2.85 & 2.68 & 5.23 & & & & & & & \\
\hline $\mathrm{Ce} / \mathrm{Ce}^{*}$ & 1.20 & 1.20 & 1.18 & 1.20 & 1.17 & 1.14 & 1.14 & & & & \\
\hline $\mathrm{Eu} / \mathrm{Eu}^{*}$ & 0.78 & 0.80 & 0.76 & 0.79 & & & & & & & \\
\hline
\end{tabular}

$\mathrm{Eff}_{\mathrm{gy}}=(\mathrm{REE} / \mathrm{Ca})_{\mathrm{gy}} /(\mathrm{REE} / \mathrm{Ca})_{\mathrm{mQ}}$

$\mathrm{Ce} / \mathrm{Ce}^{*}=\mathrm{Ce}_{\mathrm{N}} /\left(0.5 \mathrm{La}_{\mathrm{N}}+0.5 \mathrm{Pr}_{\mathrm{N}}\right)$

$\mathrm{Eu} / \mathrm{Eu}^{*}=\mathrm{Eu}_{\mathrm{N}} /\left(0.5 \mathrm{Sm}_{\mathrm{N}}+0.5 \mathrm{Dy}_{\mathrm{N}}\right)$ 
the supernatant solutions from the dissolution with Milli-Q water and gypsum-saturated water (labeled with $-\mathrm{w}$ ). Due to the very high salinity of the supernatant brines equilibrated with alunogen, rozenite, hexahydrite, and rhomboclase, the final solution required very high dilution for ICP analyses, and REEs were not detected. The complete analysis of all the samples is compiled in Table S-3. As in the previous experiment, no clear concentric mineral zonation was observed. Both the chemical analysis (Table 4) and the XRD (Fig. S-6) of the different residual solids showed that only one sulfate (saturated in the individual solutions) remained each time after selective dissolution.

Major elements in Milli-Q and gypsum-saturated water maintained the proportions of the original AMD. An exception is $\mathrm{Si}$, which always showed a depletion, suggesting its incorporation into a solid phase. Silica also showed very depleted values in the analyses of the different solid sulfates, indicating that it probably formed an unidentified mineral that is not easily dissolved in Milli-Q water. The formation of a silica mineral phase independent from sulfates was already suggested by the lack of correlation of $\mathrm{Si}$ with sulfate in the statistical analyses. Moreover, the saturation index of amorphous silica was already close to equilibrium in the six AMD samples prior to evaporation.

With respect to REEs, the most relevant feature is that very low amounts were retained in the alunogen, rozenite, hexahydrite, and rhomboclase. Only gypsum seemed to concentrate REEs, except for Sc. The amount of REE $(\mathrm{mg} / \mathrm{kg}$ ) concentrated in gypsum can be calculated as:

$[\mathrm{REE}]_{\mathrm{gy}}^{\mathrm{s}}=\frac{[\mathrm{REE}]_{\mathrm{gy}}^{\mathrm{w}}}{[\mathrm{Ca}]_{\mathrm{gy}}^{\mathrm{w}}} \frac{\mathrm{M}_{\mathrm{Ca}}}{\mathrm{M}_{\mathrm{gy}}} 10^{6}$

where $[\mathrm{REE}]_{\mathrm{gy}}^{\mathrm{w}}$ and $[\mathrm{Ca}]_{\mathrm{gy}}^{\mathrm{w}}$ y are the analytical values of REE and $\mathrm{Ca}$ in gypsum $(\mathrm{mg} / \mathrm{L})$, and $\mathrm{M}_{\mathrm{Ca}}$ and $\mathrm{M}_{\mathrm{gy}}$ are the atomic and molecular masses of $\mathrm{Ca}$ and gypsum, respectively. The
$[\mathrm{REE}]_{\mathrm{gy}}^{\mathrm{s}}$ values are listed in Table 4, resulting in a total of $2400 \mathrm{mg} \mathrm{REE} / \mathrm{kg}$ solid, a value comparable to the rates of clay deposits ( 500 to $4000 \mathrm{mg} / \mathrm{kg}$ ) enriched in more expensive HREEs, but an order of magnitude less than conventional igneous deposits rich in LREEs (Van Gosen et al. 2017).

Another important feature is the large amount of REE that remained in the gypsum-saturated solution. Indeed, the REE concentrations in such solution were similar to that of the solution resulting from the complete dissolution of salts with Milli-Q water (Table 4). This suggests that, in addition to gypsum, REE precipitated as an independent mineral(s). Unfortunately, such minerals could not be detected by FESEM-EDS. Neither could they be predicted from solubility modeling due to the absence of REE-SO $\mathrm{SO}_{4}$ Pitzer ion-ion interaction coefficients in the literature. The importance of an independent soluble mineral as an REE reservoir could be evidenced by the comparison between the REE concentrations normalized to the respective Ca content of the gypsum and the Milli-Q water. The comparison showed that gypsum concentrated between 7 and 23\% of REE, depending on the sample and the REE, with Pr and Lu being the most and least concentrated, respectively (see the Eff-gy averaged values between 7.5 and $17.5 \%$ in Table 4). Again, Sc was the exception, with a very low concentration in gypsum.

The preference of LREEs for gypsum suggested by the statistical analysis was confirmed by comparing the NASC normalized patterns of the gypsum and the coexisting saturated solution. Comparison with the original AMD pattern showed a clear enrichment of gypsum in LREEs and a depletion in HREEs (Fig. 6A). In contrast, the coexisting aqueous phase shows a less clear enrichment in HREEs and depletion in LREEs (Fig. 6B). This pattern is also confirmed by the $\Sigma \mathrm{LREE} / \Sigma \mathrm{HREE}, \mathrm{La} / \mathrm{Yb}$, and $\mathrm{Sm} / \mathrm{Y}$ indices of the gypsum, distinctly higher than those of the initial AMD or the bulk dissolution in Milli-Q water (Table 4).
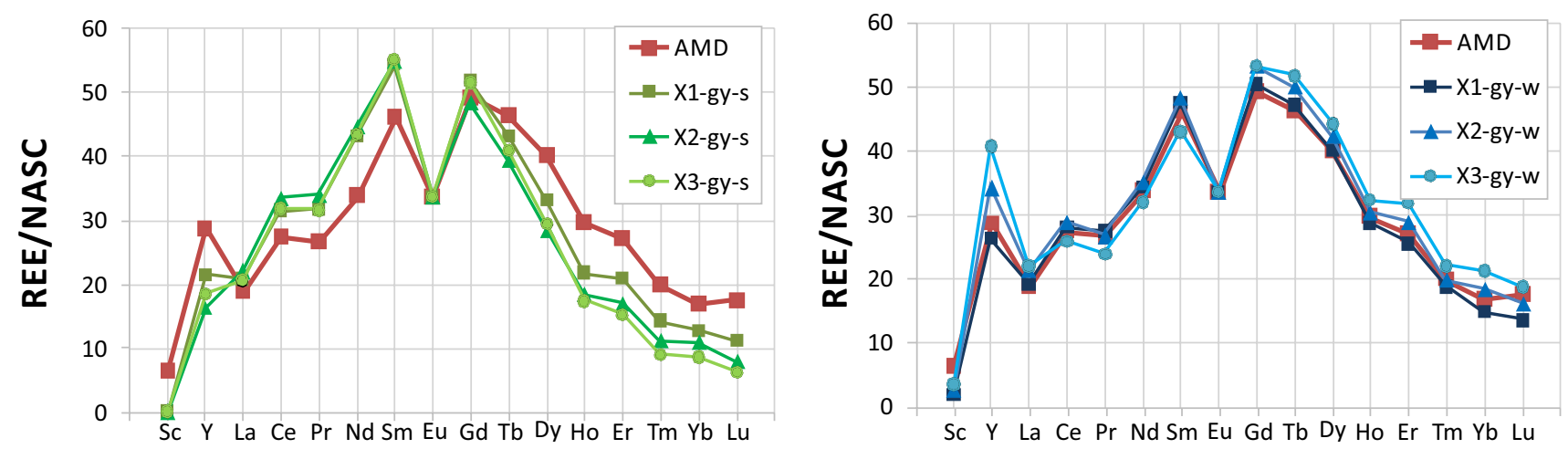

Fig. 6 REE patterns of residual gypsum (A) and the coexisting solution (B) normalized to the North American Shale Composite (NASC). The concentrations in the parent AMD are also plotted as a reference scaled to the same Eu value to enable the comparison 
This behavior of the different REEs can be numerically evidenced by the gypsum-solution partition coefficient $\mathrm{K}_{\mathrm{D}}$ $(\mathrm{L} / \mathrm{kg})$ of the individual REEs, calculated by:

$\mathrm{K}_{\mathrm{D}}=\frac{[\mathrm{REE}]_{\mathrm{gy}}^{\mathrm{s}}}{[\mathrm{REE}]_{\mathrm{gysat}}^{\mathrm{w}}}$

where $[\mathrm{REE}]_{\mathrm{gy}}^{\mathrm{s}}$ and $[\mathrm{REE}]_{\mathrm{gysat}}^{\mathrm{w}}$ are the concentrations in gypsum $(\mu \mathrm{g} / \mathrm{kg})$ and in the coexisting aqueous phase saturated with gypsum $(\mu \mathrm{g} / \mathrm{L})$, respectively. The average $\mathrm{K}_{\mathrm{D}}$ values for each element are listed in Table 4. Consistent with the similarity of their ionic radii with that of $\mathrm{Ca}$ in eight-fold coordination, the $\mathrm{K}_{\mathrm{D}}$ values are highest for Pr and Nd and systematically decrease to La and to the HREE. The same trend was shown by the $K_{D}$ values obtained by Inguaggiato et al. (2018) for a gypsum crystal and a sulfate-rich brine in the Poas volcano in Costa Rica. The absolute values reported by these authors, however, are an order of magnitude lower. This could be due to our much higher sulfate concentration that would favor the formation of REE-SO4 polyhedra within the gypsum structure.

\section{Conclusions}

Alunogen, gypsum, and $\mathrm{Fe}(\mathrm{II})$ and $\mathrm{Mg}$ sulfates with different degrees of hydration formed the major mineralogy of the salt mixture resulting from the evaporation to dryness of all six AMD samples studied. No sequential precipitation of these sulfates according to their solubility was observed by XRD, FESEM-EDS, and chemical analysis. All the REE inventories in the original AMD samples were entirely transferred to sulfates after evaporation, but no individual REE minerals could be identified.

Statistical analysis of the chemical composition of solutions from bulk dissolution of the evaporitic salts showed that only three PCs explained more than $80 \%$ of the variability in the six AMD samples analyzed. PC1 was clearly associated with $\mathrm{Ca}$ and LREEs and was interpreted as gypsum precipitation, whereas PC2 grouped HREEs, which could not be associated with any major sulfate. Finally, PC3 grouped $\mathrm{Mg}, \mathrm{Fe}(\mathrm{II})$, and several transition metals $(\mathrm{Cu}$, $\mathrm{Ni}, \mathrm{Co}, \mathrm{Mn}$, and $\mathrm{Zn}$ ) and was attributed to $\mathrm{Fe}(\mathrm{II})$ and $\mathrm{Mg}$ sulfates, as already described in previous literature. Gypsum preferentially concentrated LREEs according to their differences in atomic radius with that of $\mathrm{Ca}$ in eight-fold coordination.

Selective dissolution experiments of the evaporitic salts with solutions saturated in the individual major sulfates revealed that the REEs were only concentrated in gypsum and were practically absent in alunogen, rozenite, hexahydrite, and rhomboclase. The partition coefficients obtained in these experiments confirmed that the REE affinity for gypsum decreased from $\mathrm{Pr}-\mathrm{Nd}$ to $\mathrm{La}$ and to $\mathrm{Lu}$.

However, it was estimated that gypsum only concentrates between 10 and $20 \%$ of the total REE inventory (less than $1 \%$ in the case of Sc), with the rest probably forming one or more soluble unidentified mineral phases. Therefore, from a practical point of view, gypsum cannot be considered a relevant trap for REE or a very effective method to concentrate REE from AMD. Nevertheless, the maximum REE concentration accepted by gypsum, a mineral ubiquitous in sludge from AMD treatment, should be confirmed with further experiments if these wastes are to be considered a source of REEs.

Supplementary Information The online version contains supplementary material available at https://doi.org/10.1007/s10230-021-00803-0.

Acknowledgements This work was funded by the European EIT-Raw Materials MORECOVERY and the Spanish SCYRE (CGL201678783-C2-R) projects. F. Macías was funded by the R\&D FEDER Andalucía 2014-2020 programme through the project RENOVAME (FEDER; UHU-1255729). The authors thank M. Cabañas, R. Bartrolí, and N. Moreno (IDAEA-CSIC) for their analytical assistance, and two anonymous reviewers for their constructive comments.

\section{References}

Alonso E, Sherman AM, Wallington TJ, Everson MP, Field FR, Roth R, Kirchain RE (2012) Evaluating rare earth element availability: a case with revolutionary demand from clean technologies. Environ Sci Technol 46:3406-3414. https://doi.org/10.1021/es203 $518 \mathrm{~d}$

Alpers CN, Blowes DW, Nordstrom DK, Jambor JL (1994) Secondary minerals and acid mine-water chemistry. In: Jambor JL, Blowes DW (Eds), Environmental Geochemistry of Sulfide Mine-Wastes, Mineralogical Assoc of Canada Short Course 22: 247-270

Ayora C, Macías F, Torres E, Lozano A, Carrero S, Nieto JM, PérezLópez R, Fernández-Martínez A, Castillo Michel H (2016) Recovery of rare earth elements and ytrium from passive remediation systems of acid mine drainage. Environ Sci Technol 50:82558262. https://doi.org/10.1021/acs.est.6b02084

Basallote MD, Cnovas CR, Olias M, Perez-Lopez R, Macias F, Carrero S, Ayora C, Nieto JM (2019) Mineralogically-induced metal partitioning during the evaporative precipitation of efflorescent sulfate salts from acid mine drainage. Chem Geol 530. doi: https:// doi.org/10.1016/j.chemgeo.2019.119339

Bau M (1999) Scavenging of dissolved yttrium and rare earths by precipitating iron oxyhydroxide: experimental evidence for $\mathrm{Ce}$ oxidation, Y-Ho fractionation, and lanthanide tetrad effect. Geochim Cosmochim Acta 63:67-77. https://doi.org/10.1016/S00167037(99)00014-9

Bayless ER, Olyphant GA (1993) Acid-generating salts and their relationship to the chemistry of groundwater and storm runoff at an abandoned mine site in southwestern Indiana, USA. J Contam Hydrol 12:313-328

Buckby T, Black S, Coleman ML, Hodson ME (2003) Fe-sulphate rich evaporative mineral precipitates from the Río Tinto, southwest Spain. Miner Mag 67:263-278. https://doi.org/10.1180/00264 61036720104 
Cánovas CR, Hubbard CG, Olías M, Nieto JM, Black S, Coleman ML (2008) Hydrochemical variations and contaminant load in the Río Tinto (Spain) during flood events. J Hydrol 350:25-40. https://doi. org/10.1016/j.jhydrol.2007.11.022

Cánovas CR, Olías M, Nieto JM, Galván L (2010) Wash-out processes of evaporitic sulfate salts in the Tinto river: hydrogeochemical evolution and environmental impact. Appl Geochem 25:288-301. https://doi.org/10.1016/j.apgeochem.2009.11.014

Chakhmouradian AR, Wall F (2012) Rare earth elements: minerals, mines, magnets (and more). Elements 8:333-340. https://doi.org/ 10.2113/gselements.8.5.333

HSC Chemistry (2020) Chemical Reaction and Equilibrium Software with Extensive Thermochemical Database, version 10.0, Metso Outotec Finland Oy.

Connelly NG, Hartshorn RM, Damhus T, Hutton AT (2005) Nomenclature of Inorganic Chemistry IUPAC Recommendations, Royal Soc of Chemistry

Davis JC (2002) Statistics and data analysis in geology, 3rd Edit. John Wiley \& Sons, NYC

Delany J, Lundeen S (1990) The LLNL thermodynamic database. Technical Report UCRL-21658, Lawrence Livermore National Laboratory

Denison RE, Koepnick RB, Burke WH, Hetherington EA (1998) Construction of the Cambrian and Ordovician seawater Sr-87/Sr-86 curve. Chem Geol 152:325-340. https://doi.org/10.1016/S00092541(98)00119-3

Elderfield H, Upstill-Goddard R, Sholkovitz ER (1990) The rare earth elements in rivers, estuaries, and coastal seas and their significance to the composition of ocean. Geochim Cosmochim Acta 54:971-991. https://doi.org/10.1016/0016-7037(90)90432-K

Feldmann T, Demopoulos GP (2013) Influence of impurities on crystallization kinetics of calcium sulfate dihydrate and hemihydrate in strong $\mathrm{HCl}-\mathrm{CaCl}_{2}$ solutions. Ind Eng Chem Res 52:6540-6549. https://doi.org/10.1021/ie302933v

Fernández-Remolar DC, Morris RV, Gruener JE, Amils R, Knoll AH (2005) The Río Tinto Basin, Spain: mineralogy, sedimentary geobiology, and implications for interpretation of outcrop rocks at Meridiani Planum, Mars. Earth Planet Sc Lett 240:149-167. https://doi.org/10.1016/j.eps1.2005.09.043

Ferreira da Silva E, Bobos I, Xavier Matos J, Patinha C, Reis AP, Cardoso Fonseca E (2009) Mineralogy and geochemistry of trace metals and REE in volcanic massive sulfide host rocks, stream sediments, stream waters and acid mine drainage from the Lousal mine area (Iberian Pyrite Belt, Portugal). Appl Geochem 24:383401. https://doi.org/10.1016/j.apgeochem.2008.12.001

Fowler AD, Doig R (1983) The significance of Europium anomalies in the REE spectra of granites and pegmatites, Mont Laurier, Quebec. Geochim Cosmochim Acta 47:1131-1137

Gammons CH, Wood SA, Pedrozo F, Varekamp JC, Nelson BJ, Shope CL, Baffico G (2005) Hydrogeochemistry and rare earth element behavior in a volcanically acidified watershed in Patagonia, Argentina. Chem Geol 222:249-267. https://doi.org/10.1016/j. chemgeo.2005.06.002

Gaste-Rector SD, Blanton TN (2019) The powder diffraction file: a quality materials characterization database. Powder Diffr 34:352-360

Gimeno MJ, Auqué Sanz LF, Nordstrom DK (2000) REE speciation in low-temperature acidic waters and the competitive effects of aluminum. Chem Geol 165:167-180. https://doi.org/10.1016/ S0009-2541(99)00166-7

Glynn P (2000) Solid-solution solubilities and thermodynamics: sulfates, carbonates and halides. Rev Mineral Geochem 40:481-512. https://doi.org/10.2138/rmg.2000.40.10

Van Gosen BS, Verplanck PL, Seal RIR, Long KR, Gambogi J (2017) Critical Mineral Resources of the United States - Economic and
Environmental Geology and Prospects for Future Supply: U.S. Geologic Survey Professional Paper 1802

Gromet LP, Dymek RF, Haskin LA, Korotev RL (1984) The "North American shale composite": its compilations, major and trace element characteristics. Geochim Cosmochim Acta 48:2469-2482

Hammarstrom JM, Seal RR II, Meierb AL, Kornfeld JM (2005) Secondary sulfate minerals associated with acid drainage in the eastern US: recycling of metals and acidity in surficial environments. Chem Geol 215:407-431. https://doi.org/10.1016/j.chemgeo. 2004.06.053

Harvie CE, Møller N, Weare JH (1984) The prediction of mineral solubilities in natural waters: the $\mathrm{Na}-\mathrm{K}-\mathrm{Mg}-\mathrm{Ca}-\mathrm{H}-\mathrm{Cl}-\mathrm{SO}_{4}-\mathrm{OH}-$ $\mathrm{HCO}_{3}-\mathrm{CO}_{3}-\mathrm{CO}_{2}-\mathrm{H}_{2} \mathrm{O}$ system to high ionic strengths at $25^{\circ} \mathrm{C}$. Geochim Cosmochim Acta 48:723-751. https://doi.org/10.1016/ 0016-7037(84)90098-X

Hawthorne FC, Krivovichev SV, Burns PC (2000) The crystal chemistry of sulfate minerals. Rev Mineral Geochem 40:1-111. https:// doi.org/10.2138/rmg.2000.40.1

Hedin BC, Capo RC, Stewart BW, Hedin RS, Lopano CL, Stuckman MY (2019) The evaluation of critical rare earth element (REE) enriched treatment solids from coal mine drainage passive treatment systems. Int J Coal Geol 208:54-64. https://doi.org/10. 1016/j.coal.2019.04.007

Hubbard CR, Snyder RL (1988) RIR - measurement and use in quantitative XRD. Powder Diffr 3:74-77. https://doi.org/10.1017/S0885 715600013257

Inguaggiato C, Iñiguez E, Peiffer L, Kretzschmar T, Brusca L, MoraAmador R, Ramirez C, Bellomo S, Gonzalez G, Rouwet D (2018) REE fractionation during the gypsum crystallization in hyperacid sulphate-rich brine: the Poás Volcano crater lake (Costa Rica) exploited as laboratory. Gondwana Res 59:87-96. https://doi.org/ 10.1016/j.gr.2018.02.022

Jambor JL, Nordstrom DK, Alpers CN (2000) Metal-sulfate salts from sulfide mineral oxidation. Rev Mineral Geochem 40:303-350. https://doi.org/10.2138/rmg.2000.40.6

Jerz JK, Rimstidt JD (2003) Efflorescent sulfate minerals: paragenesis, relative stability and environmental impact. Am Mineral 88:19191932. https://doi.org/10.2138/am-2003-11-1235

Johannesson KH, Zhou XP (1999) Origin of middle rare earth element enrichments in acid waters of a Canadian high Arctic lake. Geochim Cosmochim Acta 63:153-165. https://doi.org/ 10.1016/S0016-7037(98)00291-9

Leybourne MI, Johannesson KH (2008) Rare earth elements (REE) and yttrium in stream waters, stream sediments, and Fe-Mn oxyhydroxides: fractionation, speciation, and controls over REE + $Y$ patterns in the surface environment. Geochim Cosmochim Acta 72:5962-5983. https://doi.org/10.1016/j.gca.2008.09.022

Lozano A, Ayora C, Fernández-Martínez A (2019a) Sorption of rare earth elements onto basaluminite: the role of sulfate and pH. Geochim Cosmochim Acta 258:50-62. https://doi.org/10. 1016/j.gca.2019.05.016

Lozano A, Fernández-Martínez A, Ayora C, Di-Tomamaso D, Poulain A, Rovezzi M, Marini C (2019b) Solid and aqueous speciation of yttrium in passive remediation systems of acid mine drainage. Environ Sci Technol 53:11153-11161. https://doi.org/ 10.1021/acs.est.9b01795

Lozano A, Ayora C, Macias F, Leon R, Gimeno MJ, Auque L (2020a) Geochemical behavior of rare earth elements in acid drainages: Modeling achievements and limitations. J Geochem Explor 216. doi: https://doi.org/10.1016/j.gexplo.2020.106577

Lozano A, Ayora C, Fernández-Martínez A (2020b) Sorption of rare earth elements on schwertmannite and their mobility in acid mine drainage treatments. Appl Geochem 113, doi: https://doi. org/10.1016/j.apgeochem.2019.104499

Macías F, Pérez-Lopez R, Caraballo MA, Canovas CR, Nieto JM (2017) Management strategies and valorization for waste sludge 
from active treatment of extremely metal-polluted acid mine drainage: a contribution for sustainable mining J Clean. Prod 141:1057-1066. https://doi.org/10.1016/j.jclepro.2016.09.181

McLennan SM (1989) Rare earth elements in sedimentary rocks: influence of provenance and sedimentary processes. Rev Mineral Geochem 11:169-200

McLennan SM (1994) Rare earth element geochemistry and the "tetrad" effect. Geochim Cosmochim Acta 58:2025-2033. https:// doi.org/10.1016/0016-7037(94)90282-8

Migaszewski ZM, Gałuszka A (2015) The characteristics, occurrence, and geochemical behavior of rare earth elements in the environment: a review. Crit Rev Env Sci Tec 45:429-471. https://doi.org/10.1080/10643389.2013.866622

Moncur MC, Ptacek CJ, Blowes DW, Peterson RC (2015) The occurrence and implications of efflorescent sulfate minerals at the former Sherritt-Gordon $\mathrm{Zn}-\mathrm{Cu}$ mine, Sherridon, Manitoba, Canada. Can Mineral 53:961-977. https://doi.org/10.3749/ canmin. 1500092

Noack CW, Dzombak DA, Karamalidis AK (2014) Rare earth element distributions and trends in natural waters with a focus on groundwater. Environ Sci Tech 48:4317-4326. https://doi.org/ 10.1021/es4053895

Nordstrom DK, Blowes DW, Ptacek CJ (2015) Hydrogeochemistry and microbiology of mine drainage: an update. Appl Geochem 57:3-16. https://doi.org/10.1016/j.apgeochem.2015.02.008

Olías M, Cánovas CR, Basallote MD, Lozano A (2018) Geochemical behaviour of rare earth elements (REE) along a river reach receiving inputs of acid mine drainage. Chem Geol 493:468477. https://doi.org/10.1016/j.chemgeo.2018.06.029

Olyphant GA, Carlson CP, Harper D (1991) Seasonal and stormrelated aspects of sediment yield from a rapidly eroding coal refuse deposit in southwestern Indiana. Water Resour Res 27:2825-2833. https://doi.org/10.1029/91WR01708

Parkhurst DL, Appelo CAJ (1999) User's Guide to PHREEQC (Version 2) A Computer Program for Speciation, Batch Reaction, One Dimensional Transport, and Inverse Geochemical Calculations. Water Resources Investigations Report 99-4259.

Peacor DR, Rouse RC, Essene EJ, Lauf RJ (1999) Coskrenite-(Ce), $\left.\left(\mathrm{Ce}, \mathrm{Nd}, \mathrm{L}_{\mathrm{a}}\right) 2\left({ }_{\mathrm{S}} \mathrm{O}_{4}\right) 2 \mathrm{C}_{2} \mathrm{O} 4\right) \cdot{ }_{8} \mathrm{H} 2 \mathrm{O}$, a new rare-earth oxalate mineral from Alum Cave Bluff, Tennessee: characterization and crystal structure. Can Mineral 37:1453-1462

Ptacek C, Blowes D (2000) Predicting sulfate-mineral solubilities in concentrated waters. Rev Mineral Geochem 40:513-540. https:// doi.org/10.2138/rmg.2000.40.11

Reardon EJ (1988) Ion interaction parameters for $\mathrm{AlSO}_{4}$ and application to the prediction of metal sulfate solubility in binary salt systems. J Phys Chem 92:6426-6431. https://doi.org/10.1021/ j100333a046

Reardon EJ, Beckie RD (1987) Modelling chemical equilibria of acid mine drainage. The $\mathrm{FeSO}_{4}-\mathrm{H}_{2} \mathrm{SO}_{4}-\mathrm{H}_{2} \mathrm{O}$ system. Geochim Cosmochim Acta 51:2355-2368. https://doi.org/10.1016/0016-7037(87) 90290-0

Romero A, González I, Galan E (2006) The role of efflorescent sulfates in the storage of trace elements in stream waters polluted by acid mine-drainage: the case of Peña del Hierro, southwestern Spain. Can Mineral 44:1431-1446. https://doi.org/10.2113/gscanmin. 44.6.1431

Romero FM, Prol-Ledesma R, Canet C, Alvares LN (2010) PerezVazquez R (2010) acid drainage at the inactive Santa Lucia mine, western Cuba: Natural attenuation of arsenic, barium and lead, and geochemical behavior of rare earth elements. Appl Geochem 25:716-727. https://doi.org/10.1016/j.apgeochem.2010.02.004

Rouse RC, Peacor DR, Essene EJ, Coskren TD, Lauf RJ (2001) The new minerals levinsonite-(Y) [(Y, Nd, $\mathrm{Ce}) \mathrm{Al}(\mathrm{SO} 4) 2(\mathrm{C} 2 \mathrm{O} 4) \cdot 12 \mathrm{H} 2 \mathrm{O}]$ and zugshunstite-(Ce) [(Ce, Nd, $\mathrm{La}) \mathrm{Al}(\mathrm{SO} 4) 2(\mathrm{C} 2 \mathrm{O} 4) \cdot 12 \mathrm{H} 2 \mathrm{O}]$ : coexisting oxalates with different structures and differentiation of LREE and HREE. Geochim Cosmochim Acta 65:1101-1115. https://doi.org/10.1016/S0016-7037(00)00568-8

Rull F, Guerrero J, Venegas G, Gázquez F, Medina J (2014) Spectroscopic Raman study of sulphate precipitation sequence in Rio Tinto mining district (SW Spain). Environ Sci Pollut R 21:67836792. https://doi.org/10.1007/s11356-0131927-z

Sahoo PK, Tripathy S, Equeenuddin SM, Panigrahi MK (2012) Geochemical characteristics of coal mine discharge vis-à-vis behavior of rare earth elements at Jaintia Hills coalfield, northeastern India. J Geochem Explor 112:235-243. https://doi.org/10.1016/j.gexplo. 2011.09.001

Shannon RD (1976) Revised effective ionic radii and systematic studies of interatomic distances in halides and chalcogenides. Acta Crystallogr A 32:751-767. https://doi.org/10.1107/S056773947 6001551

Snyder RL, Bish DL (1989) Quantitative Anal Rev Mineral 20:101-144

Stewart BW, Capo RC, Hedin BC, Hedin RS (2017) Rare earth element resources in coal mine drainage and treatment precipitates in the Appalachian Basin, USA. Int J Coal Geol 169:28-39. https://doi. org/10.1016/j.coal.2016.11.002

To T, Nordstrom KD, Cunningham K, Ball J, McCleskey B (1999) New method for the direct determination of dissolved Fe(III) concentration in acid mine waters. Environ Sci Technol 33:807-813. https:// doi.org/10.1021/es980684z

Tosca NJ, McLennan SM, Clark BC, Grotzinger JP, Hurotwitz JA, Knoll AH, Schroeder C, Squyres SW (2005) Geochemical modelling of evaporation processes on Mars: insight from the sedimentary record at Meridiani Planum. Earth Planet Sc Lett 240:122148. https://doi.org/10.1016/j.epsl.2005.09.042

Vass CR, Noble A, Ziemkiewicz PF (2019a) The occurrence and concentration of rare earth elements in acid mine drainage and treatment by-products: part 1-initial survey of the northern appalachian Coal Basin. Min Metall Explor 36:903-916. https://doi.org/10. 1007/s42461-019-0097-z

Vass CR, Noble A, Ziemkiewicz PF (2019b) The occurrence and concentration of rare earth elements in acid mine drainage and treatment by-products: part 2: regional survey of northern and central Appalachian Coal Basins. Min Metall Explor 36:917-929. https:// doi.org/10.1007/s42461-019-00112-9

Verplanck PL, Antweiler RC, Nordstrom DK, Taylor HE (2001) Standard reference water samples for rare earth element determinations. Appl Geochem 16:231-244. https://doi.org/10.1016/ S0883-2927(00)00030-5

Verplanck PL, Nordstrom DK, Taylor HE, Kimball BA (2004) Rare earth element partitioning between hydrous ferric oxides and acid mine water during iron oxidation. Appl Geochem 19:1339-1354. https://doi.org/10.1016/j.apgeochem.2004.01.016

Yong AG, Pearce S (2013) A beginner's guide to factor analysis: focusing on exploratory factor analysis. Tutor Quant Methods Psychol 9:79-94. https://doi.org/10.20982/tqmp.09.2.p079

Younger PL (1997) The longevity of mine water pollution: a basis for decision-making. Sci Total Environ 194-195:457-466. https:// doi.org/10.1016/S0048-9697(96)05383-1

Zhang W, Honaker RQ (2018) Rare earth elements recovery using staged precipitation from a leachate generated from coarse coal refuse. Int J Coal Geol 195:189-199. https://doi.org/10.1016/j. coal.2018.06.008

Zhang W, Honaker RQ (2020) Process development for the recovery of rare earth elements and critical metals from an acid mine leachate. Mineral Eng 153:106382. https://doi.org/10.1016/j.mineng. 2020.106382 